\title{
Optimal Option Portfolio Strategies: Deepening the Puzzle of Index Option Mispricing
}

\author{
José Afonso Faias and Pedro Santa-Clara*
}

\begin{abstract}
Traditional methods of asset allocation (such as mean-variance optimization) are not adequate for option portfolios because the distribution of returns is non-normal and the short sample of option returns available makes it difficult to estimate their distribution. We propose a method to optimize a portfolio of European options, held to maturity, with a myopic objective function that overcomes these limitations. In an out-of-sample exercise incorporating realistic transaction costs, the portfolio strategy delivers a Sharpe ratio of 0.82 with positive skewness. This performance is mostly obtained by exploiting mispricing between options and not by loading on jump or volatility risk premia.
\end{abstract}

\section{Introduction}

Although options are well known to help span states of nature (Ross (1976)) and to provide exposure to (priced) risk factors like stochastic volatility and jumps (see Bates (1996), Bakshi, Cao, and Chen (1997), Andersen, Benzoni, and Lund (2002), and Liu and Pan (2003), among others), they are seldom used in investment portfolios. ${ }^{1}$ Part of the problem is that the portfolio optimization

\footnotetext{
*Faias (corresponding author), jfaias@ucp.pt, UCP-Católica Lisbon School of Business \& Economics; Santa-Clara, psc@ novasbe.pt, Nova School of Business and Economics, NBER, and CEPR. We thank Hendrik Bessembinder (the editor) and Peter Christoffersen (the referee) for valuable comments that significantly improved the paper. We also thank Rui Albuquerque, Pierre Collin-Dufresne, Joost Driessen, Miguel Ferreira, Mark Grinblatt, José Correia Guedes, Christopher Jones, Ángel León, André Lucas, Pedro Matos, David Moreno, Andreas Rathgeber, Enrique Sentana, Ivan Shaliastovich, and participants at Nova School of Business and Economics, the Quantitative Economics Doctorate 2010 meeting at Alicante, Católica Lisbon School of Business \& Economics, the 2010 Portuguese Finance Network conference, the Finance \& Economics 2010 conference, the 2010 Foro de Finanzas, the 2011 American Finance Association annual meeting, the 2011 Professional Asset Management conference, the Oxford-Man Institute at Quantitative Finance, the 2011 EFMA annual meeting, the EcoMod2011, the conference in honor of Richard Roll and Eduardo Schwartz, the 2011 Swissquote conference, the 2011 conference on Advances in the Analysis of Hedge Fund Strategies, the Boston University, and the Research in Options conference for helpful comments and discussions. This research was funded by grant PTDC/EGE-ECO/119683/2010 from the Portuguese Foundation for Science and Technology-FCT.

${ }^{1}$ Mutual funds' use of derivatives is limited (Koski and Pontiff (1999), Deli and Varma (2002), and Almazan, Brown, Carlson, and Chapman (2004)). Mutual funds generally face legal constraints in terms of short selling, borrowing, and derivatives usage. This does not happen with hedge funds, which do use derivatives, but these represent only a small part of their holdings (Chen (2011), Aragon and Martin (2012)).
} 
methods available, like the Markowitz mean-variance model, are ill-suited to handle options.

There are three main problems in option portfolio optimization. First, the distribution of option returns departs significantly from normality and therefore cannot be described by means and (co)variances alone. Second, the short history of option returns available severely limits the precision of the estimation of their complex joint distribution, thereby adding considerable estimation error to the portfolio. ${ }^{2}$ For example, we have only data for Standard \& Poor's (S\&P) 500 options since 1996, which is not long enough to estimate reliably the moments of their joint return distribution. Third, there are high transaction costs in this market. On average, at-the-money (ATM) options have a 5\% relative bid-ask spread, while out-of-the-money (OTM) options have relative bid-ask spreads of $10 \%$. Taking these costs into account is thus critical but unfortunately hard to do within the traditional optimization approach.

We offer a simple portfolio optimization method that solves these problems: optimal option portfolio strategies (OOPS). Instead of a mean-variance objective, we maximize an expected utility function, such as power utility, which takes into account all the moments of the portfolio return distribution, penalizing negative skewness and high kurtosis. We deal with the limited sample of option returns by relying solely on historical data for the underlying asset. The only option data needed to simulate option returns are their current prices, as the payoff is fully determined by the simulations of the underlying asset. We simulate returns of the underlying asset going forward and, given the definition of option payoffs, simulate corresponding option returns. We use simple bootstrap methods fitted to index data since 1950. Plugging the simulated returns of the option portfolio into the utility function and averaging across simulations gives us an approximation of the expected utility that can be maximized to obtain optimal portfolio weights. ${ }^{3}$ This method is similar in spirit to Brandt, Santa-Clara, and Valkanov (2009).

We apply our method to a portfolio allocation problem between a risk-free asset and four European options on the S\&P 500 index with 1-month to maturity: an ATM call, an ATM put, a 5\% OTM call, and a 5\% OTM put. ${ }^{4}$ These are liquid options that can be combined to generate a variety of final payoffs. We study optimal option strategies in a realistic setting with transaction costs. To incorporate transaction costs, we follow Eraker (2013) and Plyakha and Vilkov (2008). For each option, we define two securities: a "long option" initiated at the ask quote and a "short option" initiated at the bid quote. The short options enter the optimization process with a negative signal. Finally, we impose no short selling so that only one of the two, long or short positions, is ever taken.

\footnotetext{
${ }^{2}$ This is especially problematic because the optimization process tends to amplify this estimation noise (Michaud and Michaud (2008)).

${ }^{3}$ Hedging demands and long-term horizons might be important. However, Tan (2013) finds that the benefit of adding options is small for long-horizon constant relative risk aversion (CRRA) investors, and Liu and Pan (2003) and Driessen and Maenhout (2007) show that improvements by including derivatives are driven mostly by a myopic component. Our results show low predictability of returns of the optimal strategy and little correlation with the stock market. These two features imply that there would be no hedging demand and thus little loss from our myopic approach.

${ }^{4}$ The method is usable with American options if we are willing to ignore the impact of early exercise. It is an empirical question whether the method remains useful.
} 
We study the performance of the OOPS in an out-of-sample exercise using a conservative CRRA utility function. Between Jan. 1996 and Aug. 2013, the OOPS yields an annualized certainty equivalent of $9.94 \%$ and an annualized Sharpe ratio of 0.82 . This compares well with the stock market in the same period, which had a certainty equivalent of $-1.31 \%$ and a Sharpe ratio of 0.29 . Surprisingly, OOPS returns present positive skewness and relatively low excess kurtosis, which compare favorably to simply shorting individual options. We find that our strategy loads significantly on all four options and that the optimal weights vary over time. OOPS is almost delta neutral and has a low beta of 0.03 on average. This is interesting as we expected a greater exposure to the stock market given that the return distribution on which the portfolio choice is based is calibrated to data since 1950 in which the equity Sharpe ratio was large at around 0.48 .

Besides loading on the equity premium, there could be two reasons for an investor to buy or sell options: to obtain exposure to risk premia for volatility and jump risk or to exploit option mispricing. Broadie, Chernov, and Johannes (2009) argue that there is little evidence of mispricing of options relative to the underlying stock index. However, we show that the OOPS returns are little exposed to the market, volatility, and jump risk factors identified in the literature as having significant premia, implying that the main source of returns come from exploiting mispricings of options relative to each other.

A related literature investigates the returns of simple option trading strategies. Coval and Shumway (2001) show that short positions in crash-protected, delta-neutral straddles present Sharpe ratios of around $1 .^{5}$ Driessen and Maenhout (2013) confirm these results for short-term options in U.S. and U.K. markets. Coval and Shumway (2001) and Bondarenko (2003) also find that selling naked puts offers high returns even after taking into account their considerable risk. In contrast to OOPS, all these strategies have negative skewness and high kurtosis, implying a lower (negative in many cases) certainty equivalent than ours. We find that our portfolio departs significantly from exploiting these simple strategies. For instance, there are several periods in which the OOPS is net long in options.

There are a few papers that also address optimal portfolio allocation with options. Liu and Pan (2003) model stochastic volatility and jump processes and derive the optimal portfolio policy of a CRRA investor across one stock, a 5\% OTM put option, and cash. Although they obtain an analytic solution for the optimal option allocation, they need to specify a particular parametric process for the stock dynamics and estimate its parameters. They try different parameter sets and obtain ambiguous conclusions in terms of optimal put weights. Most importantly, their approach cannot be extended to multiple options. In contrast, we can use any model (parametric or not) for the distribution of returns of the underlying asset. Our work is empirical in nature and we impose no restrictions on the number of options that can be used in the optimization problem.

Driessen and Maenhout (2007) maximize the average utility of realized returns for a portfolio of a stock, a simple option strategy, and cash. As the option strategy, they consider either an 4\% OTM put, an ATM straddle, or corresponding

${ }^{5}$ The sample period of Coval and Shumway's (2001) study is different from ours, making a comparison of Sharpe ratios impossible. 
crash-neutral strategies. They conclude that positive put holdings are never optimal given historic option returns. We find, in contrast, that optimal option weights are time varying and change signs during our sample period.

Jones (2006) studies optimal portfolios to exploit the apparent put mispricing. He uses a general nonlinear latent factor model and maximizes a constrained mean-variance objective. He circumvents the short history of data by using daily option returns. However, his model is complex, requiring 57 parameters to estimate even when only one factor is considered. This limits the practical usefulness of this approach.

Constantinides, Jackwerth, and Savov (2013) study portfolios made up of either calls or puts with a targeted moneyness. Although they find high Sharpe ratios, mostly for put strategies, these strategies yield negative skewness and high kurtosis, implying a lower (or even negative) certainty equivalent than the OOPS.

Malamud (2014) studies dynamic portfolio selection with OTM options. His approach, based on option Greeks, allows him to combine several options to obtain high Shape ratios albeit with substantial kurtosis. His approach induces large turnover, which leads to high transaction costs.

The article is organized as follows: Section II explains the method. Section III describes the data. Section IV presents the results. Section V presents concluding remarks.

\section{Portfolio Allocation}

\section{A. Method}

Let time be represented by the subscript $t$ and simulations indexed by $n$. Our portfolio allocation is implemented for one risk-free asset and a series of call and put options with 1 period to maturity. We consider call options indexed by $c$ and put options indexed by $p$. We include only assets that are not redundant by putcall parity. ${ }^{6}$ At time $t$, the value of the underlying asset is denoted by $S_{t}$ and each option $i$ has an exercise price of $K_{t, i}$. The risk-free interest rate from time $t$ to $t+1$, known at time $t$, is denoted by $r f_{t}$. For each date $t$, weights are obtained through maximization of the investor's expected utility of end-of-period wealth, which is a function of simulated portfolio returns. The latter are derived from option returns, which in turn depend on the underlying asset returns. The steps below describe the OOPS algorithm in detail. The Appendix provides a simple illustration.

1) We simulate $N \log$ returns $r_{t+1}^{n}, n=1, \ldots, N$ of the underlying asset. The simulation is performed under the empirical density and not the riskadjusted measure.

2) The returns from step 1 are used to simulate the next period's underlying asset value, given its current value:

$$
S_{t+1 \mid t}^{n}=S_{t} \exp \left(r_{t+1}^{n}\right)
$$

\footnotetext{
${ }^{6}$ Although put-call parity does not hold because of transactions costs, incorporating the stock market is still redundant because its payoff is strictly dominated by the other assets' payoffs.
} 
where $n=1, \ldots, N$, and $S_{t+1 \mid t}^{n}$ denotes the simulated underlying asset value in period $t+1$ conditional on information up to time $t$, and $S_{t}$ denotes the current underlying asset value, which is observed.

3) Using the known strike prices for call options, $K_{t, c}$, and put options, $K_{t, p}$, and 1-period simulated underlying asset values $S_{t+1 \mid t}$ from equation (1), we simulate option payoffs at their maturity $t+1$ :

$$
\begin{aligned}
& C_{t+1 \mid t, c}^{n}=\max \left(S_{t+1 \mid t}^{n}-K_{t, c}, 0\right) \quad \text { and } \\
& P_{t+1 \mid t, p}^{n}=\max \left(K_{t, p}-S_{t+1 \mid t}^{n}, 0\right),
\end{aligned}
$$

where $n=1, \ldots, N$. Using the simulated payoffs in equation (2) and observed current option prices $C_{t, c}$ and $P_{t, p}$, option returns are computed by:

$$
r_{t+1 \mid t, c}^{n}=\frac{C_{t+1 \mid t, c}^{n}}{C_{t, c}}-1 \text { and } r_{t+1 \mid t, p}^{n}=\frac{P_{t+1 \mid t, p}^{n}}{P_{t, p}}-1,
$$

where $n=1, \ldots, N$.

4) We construct simulated portfolio returns in the usual way:

(4) $r p_{t+1 \mid t}^{n}=r f_{t}+\sum_{c=1}^{C} \omega_{t, c}\left(r_{t+1 \mid t, c}^{n}-r f_{t}\right)+\sum_{p=1}^{P} \omega_{t, p}\left(r_{t+1 \mid t, p}^{n}-r f_{t}\right)$,

where $\omega_{t, c}$ and $\omega_{t, p}$ denote the call and put option weights and $n=1, \ldots, N$. Each simulated portfolio return is a weighted average of the asset returns and only the risk-free rate is not simulated.

5) We choose weights by maximizing expected utility over simulated portfolio returns

$$
\max _{\omega} \mathrm{E}\left[U\left(W_{t}\left[1+r p_{t+1 \mid t}\right]\right)\right] \approx \max _{\omega} \frac{1}{N} \sum_{n=1}^{N} U\left(W_{t}\left[1+r p_{t+1 \mid t}^{n}\right]\right) .
$$

The output is given by $\omega_{t, c}$ and $\omega_{t, p}$.

6) One-period out-of-sample performance is evaluated with realized option returns. We determine the option realized payoffs:

$$
\begin{aligned}
& C_{t+1, c}=\max \left(S_{t+1}-K_{t, c}, 0\right) \quad \text { and } \\
& P_{t+1, p}=\max \left(K_{t, p}-S_{t+1}, 0\right) .
\end{aligned}
$$

We find the corresponding returns:

$$
r_{t+1, c}=\frac{C_{t+1, c}}{C_{t, c}}-1 \text { and } r_{t+1, p}=\frac{P_{t+1, p}}{P_{t, p}}-1 .
$$

Finally, we determine the 1-period out-of-sample portfolio return:

$$
r p_{t+1}=r f_{t}+\sum_{c=1}^{C} \omega_{t, c}\left(r_{t+1, c}-r f_{t}\right)+\sum_{p=1}^{P} \omega_{t, p}\left(r_{t+1, p}-r f_{t}\right),
$$

using the weights determined ex ante in step 5. 
Our approach essentially compares the current price of an option to the expected payoff and risk of the option that follows from the assumed probability distribution of the underlying asset implicit in the simulation. If the option appears cheap relative to the expected payoff and risk profile, the investor buys it. The investor sells the option if its current price is too high relative to the expectation and risk profile of the simulated payoff at maturity.

\section{B. Return Simulation}

Our method requires the simulation of the distribution of the underlying stock market returns. It is known that the distribution of raw stock market returns is left skewed, leptokurtic, and presents autoregressive conditional heteroskedasticity $(\mathrm{ARCH})$ effects, which can be verified in Table 1 . We study historic standardized returns, $\mathrm{SR}$, as the ratio between raw returns, $\mathrm{RR}$, and their standard deviation, SDEV, as:

$$
\mathrm{SR}_{t+1}^{n}=\frac{\mathrm{RR}_{t+1}^{n}}{\mathrm{SDEV}_{t+1}}, \quad n=1, \ldots, N .
$$

From Table 1, we confirm that this series is closer to a normal distribution, although still left skewed, and no significant ARCH effects are present.

Each month after 1995, based on an expanding sample of historical standardized returns starting in 1950, we simulate different paths for standardized returns. Following Efron and Tibshirani (1993), we resample directly from the standardized empirical distribution (bootstrap). This is appropriate, as standardized returns are approximately independent and identically distributed. This approach has the same moments as the historical distribution by construction.

The final step is to scale up or down simulated returns by the current realized volatility:

$$
r_{t+1}^{n}=s r_{t+1}^{n} \times r v_{t}, \quad n=1, \ldots, N
$$

The current realized volatility is calculated from the last $d$ trading days and scaled by 21 days (the average number of trading days in a month) to get monthly units. We consider alternatives values of $d$ to be $1,5,10,20,30$, and 60 days. In

TABLE 1

S\&P 500 Index Returns: Summary Statistics

Table 1 reports summary statistics (number of observations, skewness, excess kurtosis, 1-month autocorrelation for returns, and squared returns) and tests (1-month Ljung-Box (1978)), and ARCH tests; $p$-values of each test are presented

\begin{tabular}{|c|c|c|c|c|c|c|}
\hline \multirow[b]{2}{*}{ Statistics } & \multicolumn{3}{|c|}{ Raw Returns } & \multicolumn{3}{|c|}{ Standardized Returns } \\
\hline & $\underline{1950-1995}$ & $\underline{1996-2013}$ & $\underline{1950-2013}$ & $\underline{1950-1995}$ & $\underline{1996-2013}$ & $\underline{1950-2013}$ \\
\hline No. of obs. & 551 & 212 & 763 & 551 & 212 & 763 \\
\hline $\begin{array}{l}\text { Skewness } \\
\text { Excess kurtosis }\end{array}$ & $\begin{array}{r}-0.56 \\
5.97\end{array}$ & $\begin{array}{r}-0.81 \\
4.30\end{array}$ & $\begin{array}{r}-0.66 \\
5.41\end{array}$ & $\begin{array}{r}-0.34 \\
3.60\end{array}$ & $\begin{array}{r}-0.48 \\
3.36\end{array}$ & $\begin{array}{r}-0.35 \\
3.78\end{array}$ \\
\hline $\begin{array}{l}\rho_{1}(z) \\
\rho_{1}\left(z^{2}\right) \\
Q_{1}(z)\end{array}$ & $\begin{array}{c}0.03 \\
0.13 \\
0.44 \\
{[0.51]}\end{array}$ & $\begin{array}{c}0.10 \\
0.23 \\
2.07 \\
{[0.15]}\end{array}$ & $\begin{array}{c}0.05 \\
0.16 \\
2.08 \\
{[0.15]}\end{array}$ & $\begin{array}{c}0.03 \\
-0.08 \\
0.38 \\
{[0.54]}\end{array}$ & $\begin{array}{c}0.04 \\
-0.10 \\
0.27 \\
{[0.60]}\end{array}$ & $\begin{array}{c}0.03 \\
-0.06 \\
0.64 \\
{[0.42]}\end{array}$ \\
\hline $\mathrm{ARCH}(1)$ & $\begin{array}{c}9.60 \\
{[0.00]}\end{array}$ & $\begin{array}{l}10.83 \\
{[0.00]}\end{array}$ & $\begin{array}{l}20.50 \\
{[0.00]}\end{array}$ & $\begin{array}{c}3.93 \\
{[0.05]}\end{array}$ & $\begin{array}{c}2.04 \\
{[0.15]}\end{array}$ & $\begin{array}{c}3.12 \\
{[0.08]}\end{array}$ \\
\hline
\end{tabular}
in square brackets) for raw and standardized returns of the S\&P 500 index. 
each month, we use only the realized volatility length that maximizes the expected utility in sample. ${ }^{7}$ This simple approach to incorporate time-varying volatility is close in spirit to the filtered historical simulation of Barone-Adesi, Giannopolos, and Vosper (1999), in which volatility is estimated by a parametric method such as a generalized autoregressive conditional heteroskedastic (GARCH) model instead of using past realized volatility as we do. Hull and White (1998), Diebold, Schuermann, and Stroughair (1998), and Barone-Adesi, Engle, and Mancini (2008) also build on the same idea. Of course, this model is simplistic and we ignore all the great work on GARCH, implied volatility, MIDAS (mixed data sampling), and time-varying crashes. Our point is to show that our method works well even in a simple setting such as this one.

\section{Maximizing Expected Utility}

In step 4, the investor maximizes the conditional expected utility of next period's wealth:

$$
\max _{\omega_{t, i} \in \mathbb{R}} \mathrm{E}\left[U\left(W_{t+1}\right)\right]
$$

subject to the usual budget constraint $W_{t+1}=W_{t}\left(1+r p_{t+1}\right)$. Maximizing expected utility takes into account all the moments of the return distribution. If returns are normal, investors care only about the mean and variance of portfolio returns. In practice, normality does not hold, especially for option returns. Investors thus care also about tail risk (extreme events) and asymmetry, so mean and variance do not provide enough information to make asset allocation choices.

We use the power utility function (see Brandt (1999)). This utility function presents CRRA and is given by:

$$
U(W)= \begin{cases}\frac{1}{1-\gamma} W^{1-\gamma}, & \text { if } \gamma \neq 1, \\ \ln (W), & \text { if } \gamma=1,\end{cases}
$$

where $\gamma$ is the coefficient of relative risk aversion.

This utility function is attractive for two reasons. First, because of the homotheticity property, portfolio weights are independent of the initial level of wealth. Therefore, maximizing $\mathrm{E}\left[U\left(W_{t+1}\right)\right]$ is the same as maximizing $\mathrm{E}\left[U\left(1+r p_{t}\right)\right]$. Second, investors care about all moments of the distribution, and this particular utility function penalizes negative skewness and high kurtosis. ${ }^{8}$

Bliss and Panigirtzoglou (2004) estimate an empirical risk aversion of 4 for S\&P 500 index option data. Even so, we set the CRRA parameter $\gamma$ equal to 10 in the optimization for a conservative asset allocation choice. ${ }^{9}$ Intuitively, we optimize as if the risk aversion coefficient were higher than it truly is in order to minimize in-sample overfitting. We can think of this as akin to shrinking portfolio

\footnotetext{
${ }^{7}$ We also consider other finer grids and a range-based integrated volatility estimator. The results lead to the same economic conclusions.

${ }^{8}$ We use the routine FMINCON with the active-set algorithm in MATLAB. The results are robust to different initial values.

${ }^{9}$ We run OOPS for different values of risk aversion coefficient such as 7 and 13 and the performance is similar.
} 
weights, which is often done in practice. ${ }^{10}$ Finally, note that we can use any other objective function in applying our method. ${ }^{11}$

\section{Transaction Costs}

There is a large body of literature that documents high transaction costs in the option market that are partly responsible for pricing anomalies such as violations of the put-call parity relation (see, e.g., Phillips and Smith (1980), Baesel, Shows, and Thorp (1983), and Saretto and Santa-Clara (2009)). Hence, it is essential to take these frictions into account in our optimization approach. We discuss only the impact of transaction costs measured by the bid-ask spread. Other types of costs such as brokerage fees and market price impact may be substantial but are ignored here.

Figure 1 shows bid-ask spreads for options between Jan. 1996 and Aug. 2013. Table 2 shows average bid-ask spreads of about $\$ 1.40$ for ATM options and $\$ 0.70$ for OTM options. Dividing this by mid prices, we measure relative bidask spreads for ATM options of around 5\%, increasing to $10 \%$ on average for OTM options. Relative bid-ask spreads change over time and for OTM options can reach up to $30 \% .^{12}$

We incorporate transaction costs into our approach by decomposing each option into two securities: a bid option and an ask option. We initiate long positions at the ask quote and short positions at the bid quote; shorts enter the

\section{FIGURE 1}

Bid-Ask Spread

Figure 1 represents monthly observations of the relative bid-ask spread (the ratio of the absolute bid-ask spread to the mid price) between Jan. 1996 and Aug. 2013 for four options: an at-the money (ATM) call, an ATM put, a 5\% out-of-themoney (OTM) call, and a 5\% OTM put. Each option security was created as defined in Section I. Results are provided in percentage.

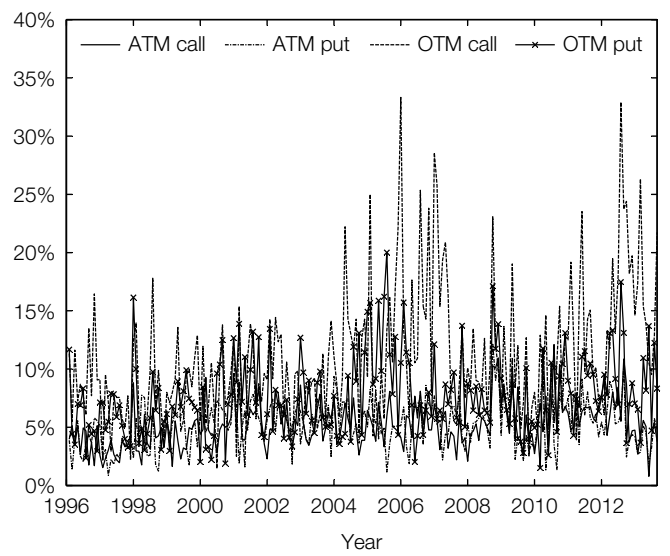

\footnotetext{
${ }^{10}$ When the optimization leads to extreme portfolio weights, due to the large simulated returns from current option prices, we use the risk-free rate in that month. We do this for realism since in practice options traders face constraints in terms of the risk exposure of their portfolios. We also tried simply using the allocation of the previous month with virtually the same results.

${ }^{11}$ Driessen and Maenhout (2007) discuss several alternatives for disappointment aversion.

${ }^{12}$ Dennis and Mayhew (2009) show that the effective spread is about two-thirds of the quoted spread given in OptionMetrics, so quoted spreads may overestimate costs, which seems a conservative assumption to use in our strategy.
} 
Table 2 reports averages of option moneyness, price, bid-ask spread, relative bid-ask spread, volume, open interest (in thousands), implied volatility, delta, beta, gamma, and vega for four options with 1 month to maturity: an at-the-money (ATM) call, an ATM put, a 5\% out-of-the-money (OTM) call, and a $5 \%$ OTM put using mid prices. Option moneyness is defined as $S / K-1$. Price is the mid option price. Bid-ask spread is the difference between ask and bid price. Relative bid-ask spread is the ratio of the bid-ask spread to the mid price. Volume is the contract's volume on the day there is 1 month to expiration. Open interest is the open interest prevalent on the same day. Implied volatility is the annualized volatility of the option using the Black-Scholes (1973) model. Delta is the Black-Scholes delta. Beta is the product of delta and the ratio of underlying asset value and option price. Gamma is the Black-Scholes gamma. Vega is the Black-Scholes vega. The period is Jan. 1996 to Aug. 2013.

\begin{tabular}{lcccc} 
& ATM Call & ATM Put & OTM Call & \multicolumn{1}{c}{ OTM Put } \\
\cline { 2 - 3 } Option moneyness & $0.24 \%$ & $-0.10 \%$ & $-4.09 \%$ & $10.87 \%$ \\
Price & 27.31 & 24.97 & 6.79 & 0.84 \\
Bid-ask spread & 1.47 & 1.37 & 0.65 & $7.68 \%$ \\
Relative bid-ask spread & $5.22 \%$ & $5.27 \%$ & $10.91 \%$ & 17,342 \\
Volume & 12,298 & 13,322 & 13,092 & 15,591 \\
Open interest $(\$ 000)$ & 15,356 & 15,756 & 15,721 & $21.83 \%$ \\
Implied volatility & $19.48 \%$ & $18.41 \%$ & $16.89 \%$ & -0.23 \\
Delta & 0.53 & -0.50 & 0.19 & -30.60 \\
Beta & 25.32 & -26.57 & 47.33 & 0.01 \\
Gamma & 0.01 & 0.01 & 0.01 & 0.99 \\
Vega & 1.33 & 1.34 & 0.84 & \\
\hline
\end{tabular}

optimization with a minus sign. This follows the approach taken by Eraker (2013) and Plyakha and Vilkov (2008). Then we run the algorithm as a constrained optimization problem by imposing a no-short-selling condition. This means that in each month only one of the securities, either the bid option or the ask option, is traded. Note that the wider the bid-ask spread, the less likely an allocation to the security is.

\section{Data}

\section{A. Securities}

We analyze the optimal option portfolio allocation from Jan. 1996 through Aug. 2013. The choice of the period relates to the availability of option data. We use $\log$ returns of the S\&P 500 index from Feb. 1950 through Aug. 2013 as the basis for the simulation process. Figure 2 presents the monthly time series of S\&P 500 and VIX indices in the portfolio allocation period. ${ }^{13}$

This is a rich period with a variety of market conditions comprising events such as the 1997 Asian crisis, the 1998 Russian financial crisis, the 1998 collapse of Long-Term Capital Management, the 2000 National Association of Securities Dealers Automated Quotations (NASDAQ) peak, the Sept. 2001 attack on New York's World Trade Center, the 2002 business corruption scandals (Enron and WorldCom), the second Gulf War, the 2006-2008 subprime mortgage crisis and Lehman Brothers default, the 2010 sovereign crisis and Flash Crash, and the Aug. 2011 stock market fall.

We use data from the OptionMetrics Ivy DB database for European options on the S\&P 500 index traded on the CBOE ${ }^{14}$ The underlying asset is the index

\footnotetext{
${ }^{13}$ The VIX index is calculated and disseminated by the Chicago Board Options Exchange (CBOE). It estimates the implied volatility of ATM options on the S\&P 500 index over the next month. The formula uses a kernel-smoothed estimator that takes as inputs the current market prices for several call and put options over a range of moneyness and maturity.

${ }^{14}$ The options trade under the ticker SPX. Average daily volume in Jan. 2013 was about 800,000 contracts.
} 
FIGURE 2

\section{S\&P 500 Index and VIX}

Figure 2 represents monthly observations of the S\&P 500 total return index and the VIX index. The period is from Jan. 1996 to Aug. 2013.

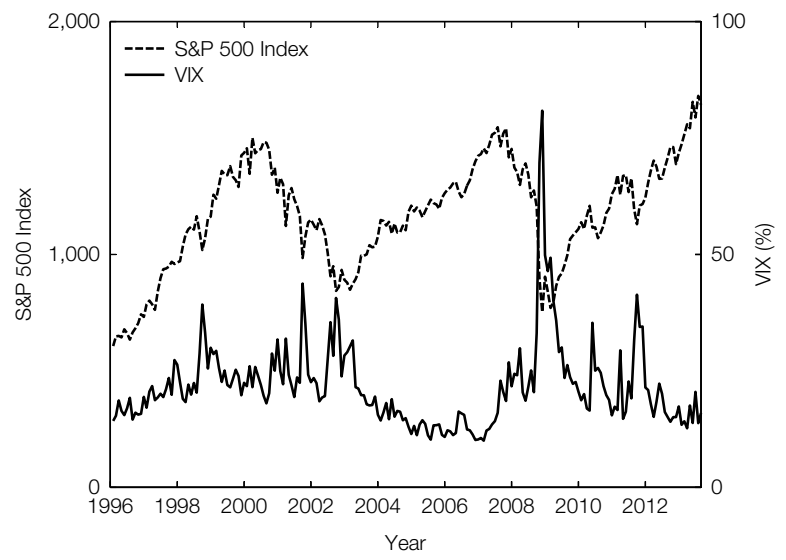

level multiplied by 100 . Option contracts expire on the third Friday of each month. The options are settled in cash on the business day following expiration. The data set includes the closing bid and ask prices, volume, and open interest for Jan. 1996 to Aug. 2013. To eliminate unreliable data, we apply a series of filters typically used in the literature. First, we exclude all observations for which the bid is lower than $\$ 0.125$ or higher than the ask price. Second, we exclude all observations with no volume to mitigate the impact of nontrading. Finally, we exclude all observations that violate arbitrage bounds.

We assume the risk-free interest rate is represented by the 1-month Treasury bill (T-bill). This series is from Bloomberg for Jan. 1996 to Aug. 2013.

\section{B. Construction of Option Returns}

Our asset allocation uses a risk-free asset and a set of risky securities. We consider four options with different levels of moneyness: an ATM call, an ATM put, a 5\% OTM call, and a 5\% OTM put. This limited number of securities keeps the model simple but still generates flexible payoffs as a function of the underlying asset price: OTM options are important for kernel spanning (Buraschi and Jackwerth (2001), Vanden (2004)) and a deep OTM put option is sensitive to crash risks. ${ }^{15}$ The options we use are among the most liquid contracts, using volume as a proxy for liquidity.

\footnotetext{
${ }^{15}$ In practice, you can use more options across moneyness or options across different assets. As an example, we consider three call options (ATM, 2\% OTM, and 7\% OTM) and three put options (ATM, 2\% OTM, and 7\% OTM), and the performance is similar. The only numerical constraint that sometimes occurs is due to redundancy of some options in some periods. This happens when moneyness of the different options values are not sufficiently apart. The problem of a portfolio with a large number of options is incurring high transaction costs prevalent in this market. This solution is, thus, in practical terms, infeasible.
} 
We choose 1-month-to-maturity options. Buraschi and Jackwerth (2001) report that most of the trading activity in S\&P 500 index options is concentrated in the nearest contracts of less than 30 days to expiration. This target maturity is also appealing as longer maturity option contracts may stop trading if the underlying asset moves in such a way that the options become deeply in the money, or OTM. Most importantly, holding the options to maturity incurs transaction costs only at inception of the trade.

We first find all available option contracts with exactly 1 month to maturity; that is, we use the returns from the Friday before the third Saturday of one month to the Friday before the third Saturday of the next month. ${ }^{16}$ We then define buckets for option moneyness in terms of the ratio of the underlying price to the strike price less $1, S / K-1$. We set a range of moneyness between $-1.0 \%$ and $1.0 \%$ for ATM options and between $2 \%$ and about $5.0 \%$ for OTM options.

For each month and bucket we are left with several potential securities from which we choose the option with the lowest relative bid-ask spread. When more than one contract has the same spread, we choose the one with the highest open interest. Finally, we construct the synthetic 1-month hold-to-expiration option returns:

$$
r_{t, t+1}=\frac{\text { PAYOFF }_{t+1}}{\text { PRICE }_{t}}-1,
$$

where PAYOFF $_{t+1}$ is the payoff of the option at maturity calculated using the closing price of the underlying asset on the day before settlement, and $\mathrm{PRICE}_{t}$ is the option price observed at the beginning of the period. We obtain a time series of 212 observations for each security.

Figure 3 presents histograms of each option return. For the options considered, we confirm that the option return distributions depart significantly from the normal distribution with considerable negative tail risk. Mean time-series characteristics for each option by moneyness are presented in Table 2. ATM call and put options have average moneyness of $0.24 \%$ and $-0.10 \%$, respectively, and OTM call and put options have average moneyness of $-4.09 \%$ and $4.37 \%$, respectively. These numbers show how close each contract is to the target of each bucket. Volume for each contract is around 13,000 and open interest is close to 15 million. Mean implied volatility varies with moneyness from $17 \%$ to $22 \%$, confirming the well-known smile effect.

Table 3 reports summary statistics of returns for the securities. We compute the certainty equivalent of an investor with a CRRA utility function with a risk aversion parameter of 4 , which is given by

$$
\mathrm{CE}=[(1-\gamma) \bar{U}]^{1 /(1-\gamma)}-1
$$

where $\gamma$ is $4, \bar{U}=\frac{1}{T} \sum_{t=1}^{T} U_{t}$, and $U_{t}$ is the CRRA utility function for each month $t$. We use a risk aversion coefficient of 4 to evaluate the returns of the strategy. This is lower than the coefficient used in the optimization. Intuitively, we optimize as if the risk aversion coefficient were higher than it truly is in reality to

\footnotetext{
${ }^{16}$ There are other alternatives that we do not follow. For example, Buraschi and Jackwerth (2001), Coval and Shumway (2001), and Driessen and Maenhout (2013) select options on the first day of each month and compute returns until the first day of the next month.
} 


\section{FIGURE 3}

\section{Densities of Monthly Option Returns}

Figure 3 represents the histograms of monthly raw returns of a long position in at-the-money (ATM) and 5\% out-of-themoney (OTM) options over the S\&P 500 index. The period is Jan. 1996 to Aug. 2013.
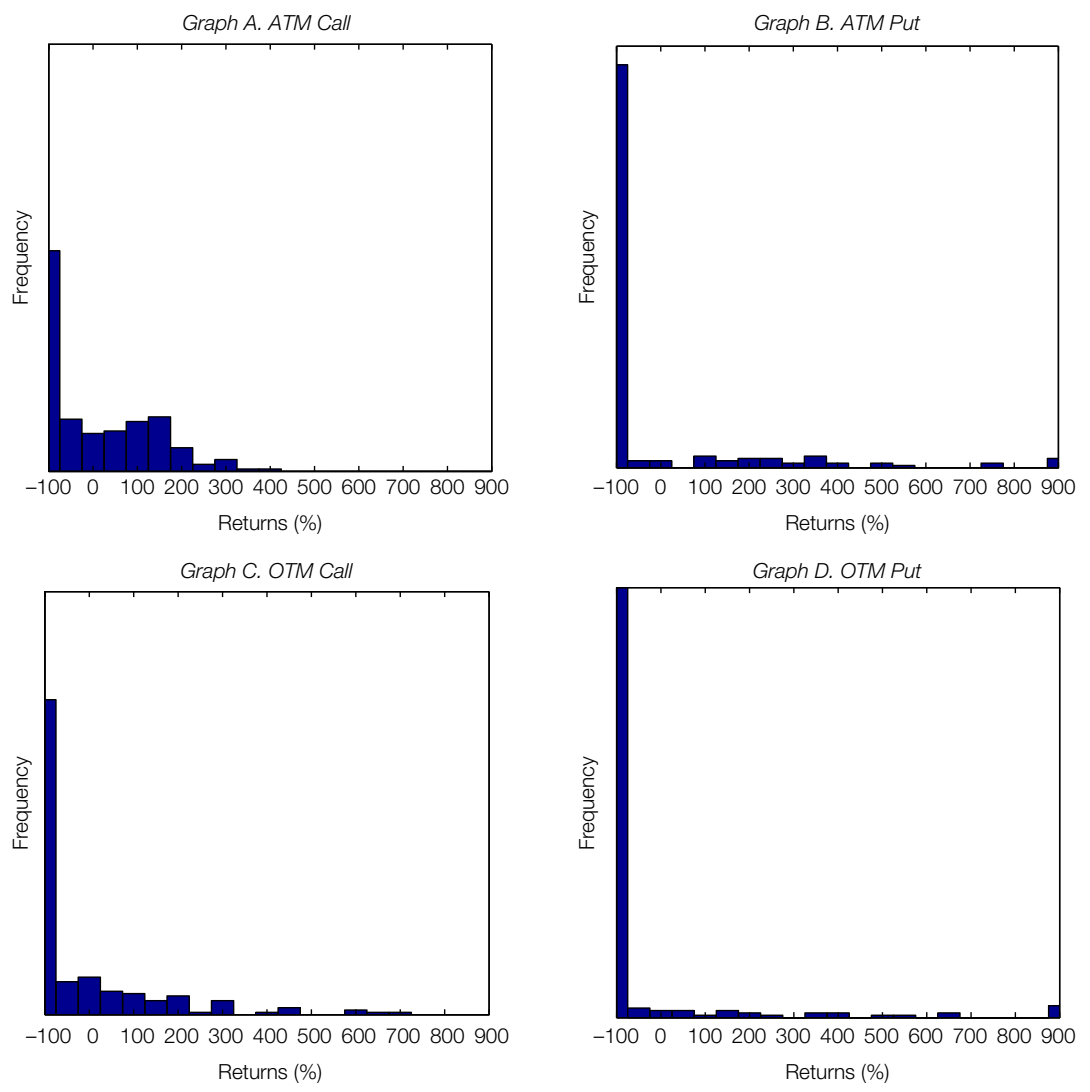

minimize in-sample overfitting. We can think of this as akin to shrinking portfolio weights, which is often done in practice. We also compute the Sharpe ratio and offer descriptive statistics of the return distribution, in particular, skewness and excess kurtosis. ${ }^{17}$ We use the S\&P 500 total return index as a benchmark. ${ }^{18}$ The S\&P 500 total return index has an average annualized return of $6.4 \%$ over the sample period, corresponding to an annualized certainty equivalent of $-1.31 \%$

\footnotetext{
${ }^{17}$ The main problem with the Sharpe ratio in this setup is that it takes into account only the first two moments, the mean and the standard deviation. See Bernardo and Ledoit (2000) and Ingersoll, Spiegel, Goetzmann, and Welch (2007) for problems with the Sharpe ratio. Broadie et al. (2009) show that although the Sharpe ratio is not the best measure to evaluate performance in an option framework, other alternative measures such as Leland's alpha or the manipulation-proof performance metric face the same problems.

${ }^{18} \mathrm{We}$ also construct a portfolio consisting of the stock market and the T-bill optimized each month using the CRRA bootstrap method defined in Section II. The performance is similar although with lower and less volatile returns.
} 


\begin{tabular}{|c|c|c|c|c|c|c|c|c|}
\hline & $\begin{array}{c}\text { Ann. } \\
\text { Mean } \\
\end{array}$ & $\begin{array}{c}\text { Ann. } \\
\text { Std. Dev. }\end{array}$ & Min. & Max. & Skew. & $\begin{array}{l}\text { Exc. } \\
\text { Kurt. } \\
\end{array}$ & $\begin{array}{c}\text { Ann. } \\
\text { CE }\end{array}$ & $\begin{array}{c}\text { Ann. } \\
\text { SR } \\
\end{array}$ \\
\hline \multicolumn{9}{|c|}{$\underline{\text { Panel A. Primitive Assets }}$} \\
\hline $\begin{array}{l}\text { S\&P } 500 \\
\text { 1-month T-bill }\end{array}$ & $\begin{array}{l}6.4 \% \\
1.1 \%\end{array}$ & $\begin{array}{r}18.2 \% \\
0.2 \%\end{array}$ & $\begin{array}{r}-29.5 \% \\
0.0 \%\end{array}$ & $\begin{array}{r}18.6 \% \\
0.2 \%\end{array}$ & $\begin{array}{r}-1.24 \\
0.07\end{array}$ & $\begin{array}{r}5.57 \\
-1.59\end{array}$ & $\begin{array}{l}-1.31 \% \\
-\end{array}$ & $\begin{array}{l}0.29 \\
-\end{array}$ \\
\hline \multicolumn{9}{|c|}{$\underline{\text { Panel B. Only Options }}$} \\
\hline $\begin{array}{l}\text { ATM call } \\
\text { ATM put } \\
\text { OTM call } \\
\text { OTM put } \\
1 / N \text { rule }\end{array}$ & $\begin{array}{r}52.4 \% \\
-209.7 \% \\
-131.3 \% \\
-440.2 \% \\
-182.2 \%\end{array}$ & $\begin{array}{l}415.6 \% \\
528.9 \% \\
947.0 \% \\
738.0 \% \\
390.0 \%\end{array}$ & $\begin{array}{l}-100 \% \\
-100 \% \\
-100 \% \\
-100 \% \\
-100 \%\end{array}$ & $\begin{array}{r}409 \% \\
703 \% \\
2,496 \% \\
1,265 \% \\
664 \%\end{array}$ & $\begin{array}{l}0.91 \\
2.44 \\
5.38 \\
4.15 \\
2.73\end{array}$ & $\begin{array}{r}-0.12 \\
6.28 \\
38.17 \\
17.88 \\
9.14\end{array}$ & $\begin{array}{l}-100.00 \% \\
-100.00 \% \\
-100.00 \% \\
-100.00 \% \\
-100.00 \%\end{array}$ & $\begin{array}{r}0.12 \\
-0.40 \\
-0.14 \\
-0.60 \\
-0.47\end{array}$ \\
\hline \multicolumn{9}{|c|}{ Panel C. Delevered Options } \\
\hline $\begin{array}{l}\text { ATM call } \\
\text { ATM put } \\
\text { OTM call } \\
\text { OTM put } \\
1 / N \text { rule }\end{array}$ & $\begin{array}{r}-1.2 \% \\
10.5 \% \\
7.0 \% \\
20.8 \% \\
9.2 \%\end{array}$ & $\begin{array}{l}18.6 \% \\
23.6 \% \\
42.3 \% \\
33.0 \% \\
17.4 \% \\
\end{array}$ & $\begin{array}{l}-18 \% \\
-31 \% \\
-111 \% \\
-57 \% \\
-30 \%\end{array}$ & $\begin{array}{l}5 \% \\
5 \% \\
5 \% \\
5 \% \\
5 \% \\
\end{array}$ & $\begin{array}{l}-0.91 \\
-2.44 \\
-5.38 \\
-4.16 \\
-2.72\end{array}$ & $\begin{array}{r}-0.13 \\
6.30 \\
38.16 \\
17.90 \\
9.12 \\
\end{array}$ & $\begin{array}{r}-8.42 \% \\
-4.93 \% \\
-100.00 \% \\
-31.78 \% \\
1.32 \%\end{array}$ & $\begin{array}{r}-0.12 \\
0.40 \\
0.14 \\
0.60 \\
0.47\end{array}$ \\
\hline
\end{tabular}

and an annualized Sharpe ratio of $0.29 .{ }^{19}$ This Sharpe ratio is lower than for the entire sample, reflecting the low returns in the recent period. S\&P 500 index returns are negatively skewed and leptokurtic. Panel B presents the same summary statistics for individual options. Options present large negative average annualized returns ranging from $-440 \%$ to $-131 \%$, except the ATM call with a positive mean return of $52 \%$. This suggests that writing options would have been a good strategy, with annualized Sharpe ratios ranging from 0.14 to 0.60 for this period. ${ }^{20}$ Writing options, however, has negative tail risk that is onerous in some months. The returns to writing options have a maximum of $100 \%$, but the minimum ranges from $-2,496 \%$ to $-664 \%$ depending on the option. This leads to large negative skewness and excess kurtosis as high as 38 and a deeply negative certainty equivalent of $-100 \%$. The last row of Panel B shows a strategy that allocates the same weight to each option. DeMiguel, Garlappi, and Uppal (2009) argue that a naive $1 / N$ uniform rule is generally a good strategy. Using this rule for our four risky assets, we obtain smoother skewness and kurtosis, and an annualized Sharpe ratio of 0.47 . However, as with individual options, the certainty equivalent is still $-100 \%$. We note that looking at these extremely levered securities may lead to unreasonable returns. No investor would invest all wealth in them. We therefore construct low-leverage portfolios that short only $4.47 \%$ of the wealth in each option and go long $104.47 \%$ in the risk-free asset. This choice allows us to relate the returns of individual options to our OOPS returns later, as OOPS invests, on average, $104.47 \%$ in the risk-free asset and has an average short position of $4.47 \%$ in options. Of course, mean, standard deviation, minimum, and maximum drop

\footnotetext{
${ }^{19}$ This negative certainty equivalent is due to the low return, high volatility, and large drawdowns of the market in this period, as well as the high risk aversion of our investor.

${ }^{20}$ Coval and Shumway (2001) and Eraker (2013) show that writing put options earns Sharpe ratios of 0.68 or above for a different period.
} 
dramatically while skewness, excess kurtosis, and annualized Sharpe ratio do not. However, the simple option strategies still deliver negative skewness returns and in most cases negative certainty equivalents, showing that risk-averse investors would not want to use them.

\section{Results}

\section{A. Out-of-Sample OOPS Returns}

Figure 4 presents the distribution of OOPS out-of-sample returns. In contrast to individual options, the OOPS is closer to a normal distribution with a symmetric shape and low tail risk. Table 4 reports summary statistics of out-of-sample returns for the OOPS and the S\&P 500 total return index (for comparison) between Jan. 1996 and Aug. 2013. Our strategies deliver an annualized certainty equivalent of $9.94 \%$ after transaction costs, which contrasts the S\&P 500 certainty equivalent of $-1.31 \%$. The OOPS yields an average annualized return of $16.1 \%$ and an annualized standard deviation of $18.4 \%$. This implies an annualized

FIGURE 4

OOPS Return Distribution

Figure 4 presents the distribution of out-of-sample 1-month optimal option portfolio strategies (OOPS) returns. The OOPS returns are after transaction costs. The period is Jan. 1996 to Aug. 2013.

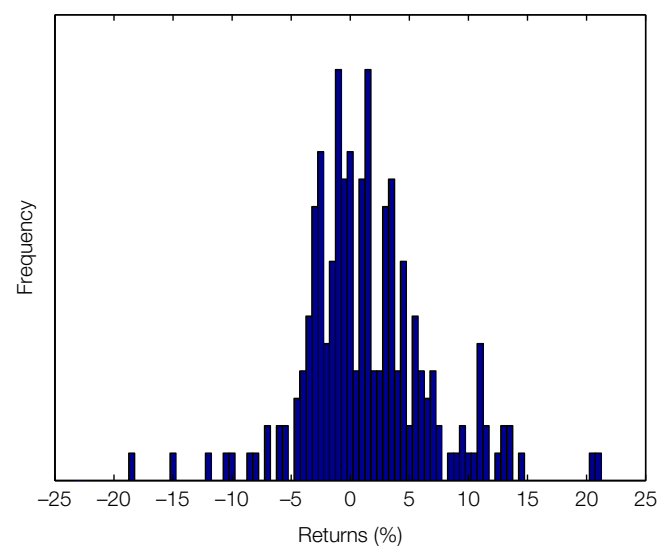

TABLE 4

Out-of-Sample OOPS Returns

Table 4 reports time-series summary statistics (annualized mean, annualized standard deviation, minimum, maximum, skewness, excess kurtosis, annualized certainty equivalent (CE), and annualized Sharpe ratio (SR)) for the S\&P 500 total return index and the out-of-sample optimal option portfolio strategies (OOPS) returns as explained in Section I. The OOPS returns are after transaction costs. The period is Jan. 1996 to Aug. 2013.

\begin{tabular}{|c|c|c|c|c|c|c|c|c|}
\hline & $\begin{array}{l}\text { Ann. } \\
\text { Mean }\end{array}$ & $\begin{array}{c}\text { Ann. } \\
\text { Std. Dev. }\end{array}$ & Min. & Max. & Skew. & $\begin{array}{l}\text { Exc. } \\
\text { Kurt. }\end{array}$ & $\begin{array}{l}\text { Ann. } \\
\text { CE }\end{array}$ & $\begin{array}{l}\text { Ann. } \\
\text { SR } \\
\end{array}$ \\
\hline S\&P 500 & $6.4 \%$ & $18.2 \%$ & $-29.5 \%$ & $18.6 \%$ & -1.24 & 5.57 & $-1.31 \%$ & 0.29 \\
\hline OOPS & $16.1 \%$ & $18.4 \%$ & $-18.4 \%$ & $20.8 \%$ & 0.35 & 2.03 & $9.94 \%$ & 0.82 \\
\hline
\end{tabular}


Sharpe ratio of $0.82 .{ }^{21}$ The S\&P 500 total index returns present lower mean and larger standard deviation, which imply a relatively lower annualized Sharpe ratio in this period of 0.29 . In contrast to the stock market, OOPS has positive skewness and low kurtosis. This is remarkable because shorting individual options has large negative skewness and much higher kurtosis. The OOPS has a minimum return of $-18.4 \%$ and a maximum return of $20.8 \%$, which compares to the S\&P 500 index minimum of $-29.5 \%$ and a maximum of $18.6 \%$.

Figure 5 presents the cumulative returns for the OOPS, S\&P 500 total return index, and risk-free rate starting from \$100 invested in Jan. 1996. The OOPS shows a relatively stable increasing pattern. The final value is more than 13 times the initial amount invested, well above the performance of the S\&P 500 index. The largest OOPS loss $(-18 \%)$ was associated with the 9/11 terrorist attacks. The second largest OOPS loss $(-15 \%)$ was associated with the Flash Crash on May 6, 2010. We cannot relate the third largest OOPS loss to any special event. On the other side, Mar. 2009 was the inflection point after the 2007-2008 crash. May 2013 and Feb. 1996 did not have salient events, although associated with the largest OOPS gains. An investor may be worried by the OOPS return drawdowns. Nevertheless, the OOPS return drawdowns are typically less severe than drawdowns for the S\&P 500 index returns. This can also be confirmed by the positive certainty equivalent of OOPS returns when compared to the negative certainty equivalent of the stock market returns.

Another concern is neglecting price impact costs for OTM puts, as the market is fairly one-sided for this option. To test this concern, we run our method but remove the possibility of selling OTM puts while still allowing them to be bought.

\section{FIGURE 5}

\section{OOPS Cumulative Returns}

Figure 5 presents out-of-sample 1-month optimal option portfolio strategies (OOPS) cumulative returns. The OOPS returns are after transaction costs. The period is Jan. 1996 to Aug. 2013.

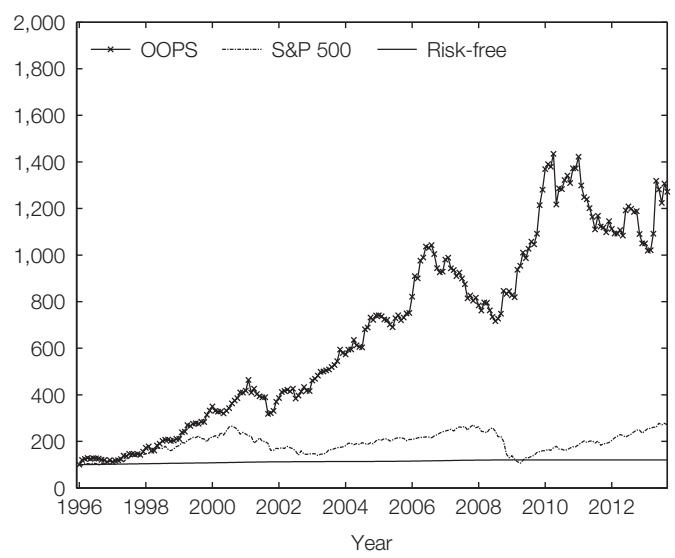

\footnotetext{
${ }^{21}$ We tried our method for 2-month and 3-month options. For 2-month options, our method delivers a Sharpe ratio of 0.81 and a certainty equivalent of $4.91 \%$. For 3-month options, our method delivers a Sharpe ratio of 0.42 and a certainty equivalent of $8.14 \%$.
} 
Alternatively, we also run the method when the bid-ask spread for OTM puts is doubled. In both cases, the impact on performance is marginal because the strategy does not meaningfully short these options.

The OOPS is different from the simple short put and other strategies described in the literature (Coval and Shumway (2001), Saretto and Santa-Clara (2009)). Table 5 reports the average, minimum, and maximum net weights of each option in the strategy, and Figure 6 presents the evolution of net weights for each option. Optimal call and put option weights vary significantly over time, ranging from $-8.7 \%$ to $3.5 \%$. Put options have generally lower weights relative to call options. On average, the OOPS takes low short positions in options. Nonetheless, there are extended periods in which the OOPS is long in options. There is an offsetting effect within ATM options and within OTM options. ${ }^{22}$

TABLE 5

OOPS Weights

Table 5 presents time-series mean, minimum, and maximum weights for each risky security of the optimal option portfolio strategies (OOPS). The period is Jan. 1996 to Aug. 2013. ATM stands for at the money, and OTM stands for out of the money.

\begin{tabular}{lrrrr} 
& ATM Call & ATM Put & OTM Call & OTM Put \\
\cline { 2 - 3 } & $-2.5 \%$ & $-1.8 \%$ & $0.2 \%$ & $-0.4 \%$ \\
Minimum & $-8.7 \%$ & $-8.4 \%$ & $-3.8 \%$ & $-4.2 \%$ \\
Maximum & $1.8 \%$ & $3.2 \%$ & $3.5 \%$ & $0.9 \%$ \\
\hline
\end{tabular}

Graph D in Figure 6 describes the evolution of the risk-free security weight, which is $100 \%$ minus the sum of the weights invested in options. The mean riskfree weight is $104.47 \%$, ranging from $94 \%$ to $116 \%$. In line with our expectation, OOPS is a net seller of options on average, but in $27 \%$ of the months our investor holds a net long position (on average equal to 3\%). Driessen and Maenhout (2007) show that CRRA investors always find it optimal to short OTM puts, and only with distorted probability assessments using cumulative prospect theory and anticipated utility are they able to obtain positive weights for puts. In contrast, we find that there are many periods when this does not apply. For example, in July 1997, the OOPS takes a long position of $0.7 \%$ in OTM put options. In Driessen and Maenhout's setting, they have a static setting, constant weights in each option over time, and a smaller opportunity set, only one option strategy at a time. It is clearly not the case that the OOPS simply sells volatility at all times. There is a strong correlation, 0.94 , between the sum of call weights and the sum of put weights. Figure 6 shows that the optimal portfolio is short OTM puts most of the time ( $85 \%$ of the months), but partially hedges this position with other options.

\section{Choice of Volatility Estimator}

The OOPS uses current realized volatility, which is calculated from the last $d$ trading days and scaled by 21 days (the average number of trading days in a month) to express it in monthly units. In each month, we use the length $d$ that maximizes the expected utility in sample. Alternatively, we also use

\footnotetext{
${ }^{22}$ Correlation figures confirm these results. The strongest correlated pair of weights is the ATM call and puts on the order of 0.82 .
} 
FIGURE 6

OOPS Time-Series Weights

Figure 6 shows the monthly weights of the optimal option portfolio strategies (OOPS). Graph A presents weights for the at-the-money (ATM) call minus put (C - P) options. Graph B presents weights for the $5 \%$ out-of-the-money (OTM) call and put options. Graph C presents weights for the difference between ATM options and OTM options. Graph D presents the weight of the risk-free security. The period is Jan. 1996 to Aug. 2013.
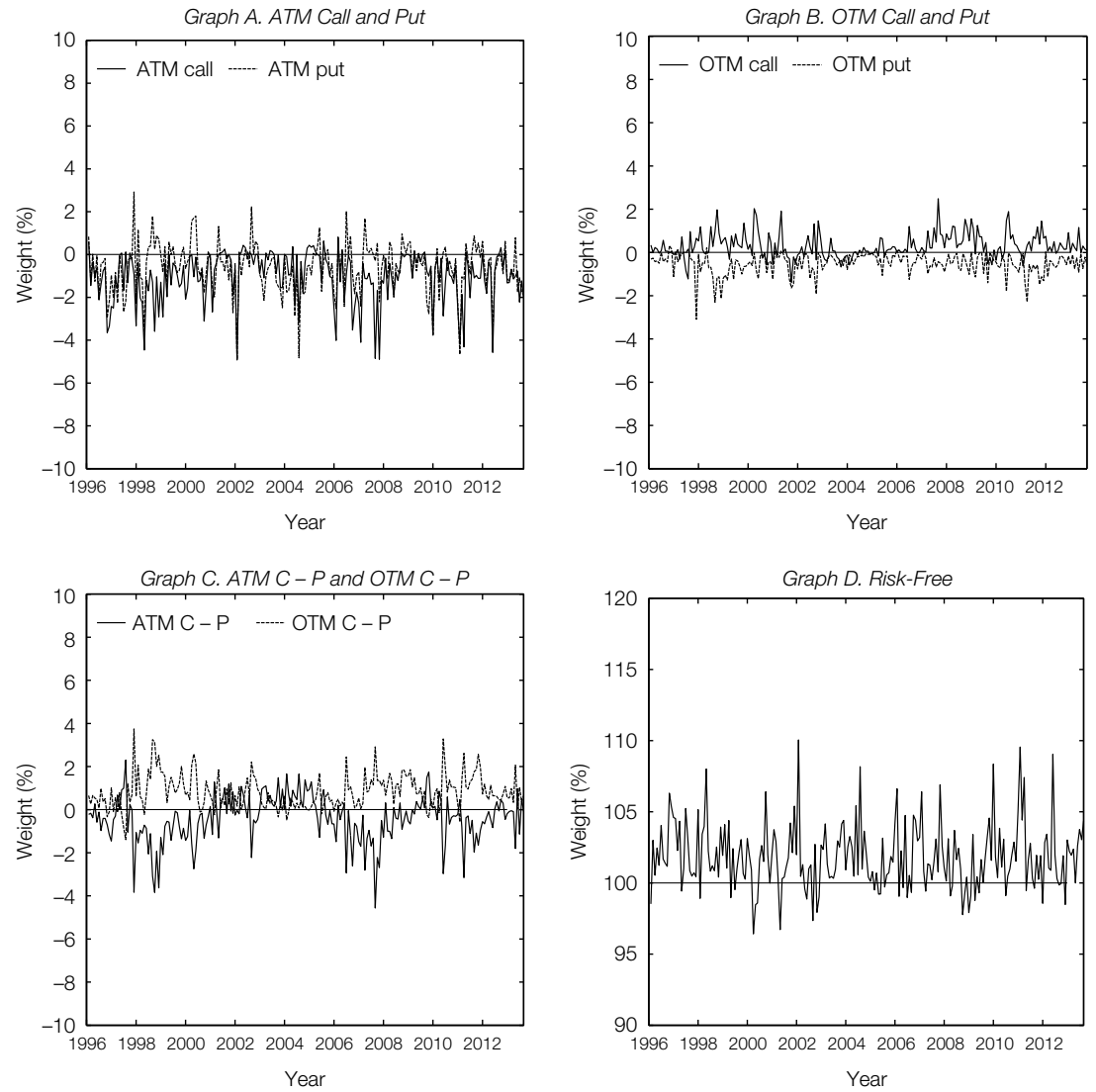

the VIX, the RiskMetrics estimate, or a fixed length of $d$ for computing realized volatility. The RiskMetrics model assumes that the variance process is given by $\sigma_{t}^{2}=\lambda \sigma_{t-1}^{2}+(1-\lambda) r_{t-1}^{2}$ where $0 \leq \lambda \leq 1$ is the smoothing parameter. The smaller the smoothing parameter, the greater weight is given to recent return data. We present the results of using these estimators for the OOPS in Table 6. The OOPS returns are robust to the choice of volatility estimator, although there is some deterioration of performance when using VIX, RiskMetrics, and different fixed levels for $d$. The decrease in performance from using VIX shows that part of the OOPS returns are due to an underestimation of volatility immediately following a positive shock to volatility. Alternatively, it may be that VIX overshoots the true volatility. The results using RiskMetrics are also enlightening. With higher $\lambda$ and stronger persistence of the estimator, we get worse performance for the OOPS. This means that the performance of our method depends on using recent 
TABLE 6

Out-of-Sample OOPS Returns: Different Volatility Estimators

Table 6 reports time-series summary statistics (annualized mean, annualized standard deviation, minimum, maximum, skewness, excess kurtosis, annualized certainty equivalent (CE), and annualized Sharpe ratio (SR)) for the out-of-sample optimal option portfolio strategies (OOPS) returns for different estimators of volatility. We present in parentheses the estimator used. RV stands for realized volatility, RM stands for RiskMetrics, and VIX stands for VIX. OOPS returns are after transaction costs. The period is Jan. 1996 to Aug. 2013.

\begin{tabular}{|c|c|c|c|c|c|c|c|c|}
\hline & $\begin{array}{l}\text { Ann. } \\
\text { Mean }\end{array}$ & $\begin{array}{c}\text { Ann. } \\
\text { Std. Dev. }\end{array}$ & Min. & Max. & Skew. & $\begin{array}{l}\text { Exc. } \\
\text { Kurt. }\end{array}$ & $\begin{array}{c}\text { Ann. } \\
\text { CE }\end{array}$ & $\begin{array}{l}\text { Ann. } \\
\text { SR }\end{array}$ \\
\hline \multicolumn{9}{|l|}{ OOPS (RV) } \\
\hline Optimal $d$ & $16.1 \%$ & $18.4 \%$ & $-18.4 \%$ & $20.8 \%$ & 0.35 & 2.03 & $9.94 \%$ & 0.82 \\
\hline$d=1$ & $11.1 \%$ & $14.4 \%$ & $-11.6 \%$ & $20.8 \%$ & 2.04 & 7.44 & $8.23 \%$ & 0.75 \\
\hline$d=5$ & $11.9 \%$ & $13.8 \%$ & $-12.9 \%$ & $20.4 \%$ & 0.93 & 4.47 & $8.65 \%$ & 0.79 \\
\hline$d=10$ & $7.8 \%$ & $12.1 \%$ & $-15.2 \%$ & $16.1 \%$ & 0.07 & 4.89 & $4.97 \%$ & 0.56 \\
\hline$d=20$ & $3.7 \%$ & $11.1 \%$ & $-18.4 \%$ & $11.7 \%$ & -1.52 & 8.59 & $0.95 \%$ & 0.23 \\
\hline$d=30$ & $2.1 \%$ & $9.5 \%$ & $-15.2 \%$ & $7.6 \%$ & -2.06 & 9.06 & $0.05 \%$ & 0.11 \\
\hline \multicolumn{9}{|l|}{ OOPS (RM) } \\
\hline$\lambda=0.80$ & $9.3 \%$ & $12.1 \%$ & $-13.9 \%$ & $19.6 \%$ & 0.61 & 6.11 & $6.61 \%$ & 0.68 \\
\hline$\lambda=0.90$ & $5.9 \%$ & $10.1 \%$ & $-15.2 \%$ & $14.9 \%$ & -0.41 & 8.33 & $3.87 \%$ & 0.48 \\
\hline$\lambda=0.96$ & $3.7 \%$ & $8.8 \%$ & $-14.5 \%$ & $9.9 \%$ & -1.38 & 9.57 & $2.12 \%$ & 0.31 \\
\hline OOPS (VIX) & $6.6 \%$ & $11.2 \%$ & $-16.8 \%$ & $16.0 \%$ & -0.33 & 7.75 & $4.03 \%$ & 0.49 \\
\hline
\end{tabular}

information to estimate volatility. We see the same results as we vary the length of the window to estimate volatility. It is particularly important for our method to put the most weight on recent observations.

\section{B. Risk or Mispricing?}

There are two alternative justifications for the OOPS performance: loading in priced risk factors or exploiting option mispricing. The existing literature supports both hypotheses. Bakshi et al. (1997), Bates (1996), Chernov and Ghysels (2000), Duffie, Pan, and Singleton (2000), Pan (2002), Liu and Pan (2003), Eraker (2004), Broadie, Chernov, and Johannes (2007), Todorov (2010), and Christoffersen, Jacobs, and Heston (2013) show that option prices reflect priced volatility and crash risk exposures, whereas Coval and Shumway (2001), Jackwerth (2000), Jones (2006), Saretto and Goyal (2009), and Constantinides et al. (2013) show that risk factor exposures do not fully explain option prices. In this section, we explore the two alternatives.

We find that the OOPS has low exposure to priced risk factors. Ex ante, our strategies have, on average, low exposure to the market, volatility, and jump risks. There are, however, some periods in which the OOPS is more exposed, especially when volatility is low. Figure 7 presents the time-series evolution of three risk measures from Jan. 1996 to Aug. 2013. We use Greeks from Black and Scholes (1973) to evaluate this. The beta of an option is computed by multiplying the Black-Scholes delta by the ratio between the underlying asset value and the option value. The portfolio beta is the weighted average of the option betas. ${ }^{23}$ This measure has the advantage that it takes into account option leverage. The OOPS has lower beta than individual options. ${ }^{24}$ It varies between -0.75 and 0.62 with a mean of 0.03 . This means beta is not significantly different from 0 using a Newey-West (1987) $t$-statistic.

\footnotetext{
${ }^{23}$ We do not present the delta, because its time-series distribution is narrow and close to 0 .

${ }^{24}$ Beta for individual options is presented in Table 2 and the differences between individual option betas and OOPS betas are statistically significant.
} 


\section{FIGURE 7}

\section{OOPS Time-Series Risk Measures}

Figure 7 presents the optimal option portfolio strategies (OOPS) risk measures calculated according to the Black-Scholes (1973) model. Beta is the percentage change in the portfolio due to a 1-percent change in the underlying price. Percent vega is the percentage change in the portfolio due to a 1-percentage-point change in the volatility. Market jump of $-5 \%$ is the percentage change in portfolio if the stock market drops 5\%. The period is Jan. 1996 to Aug. 2013.
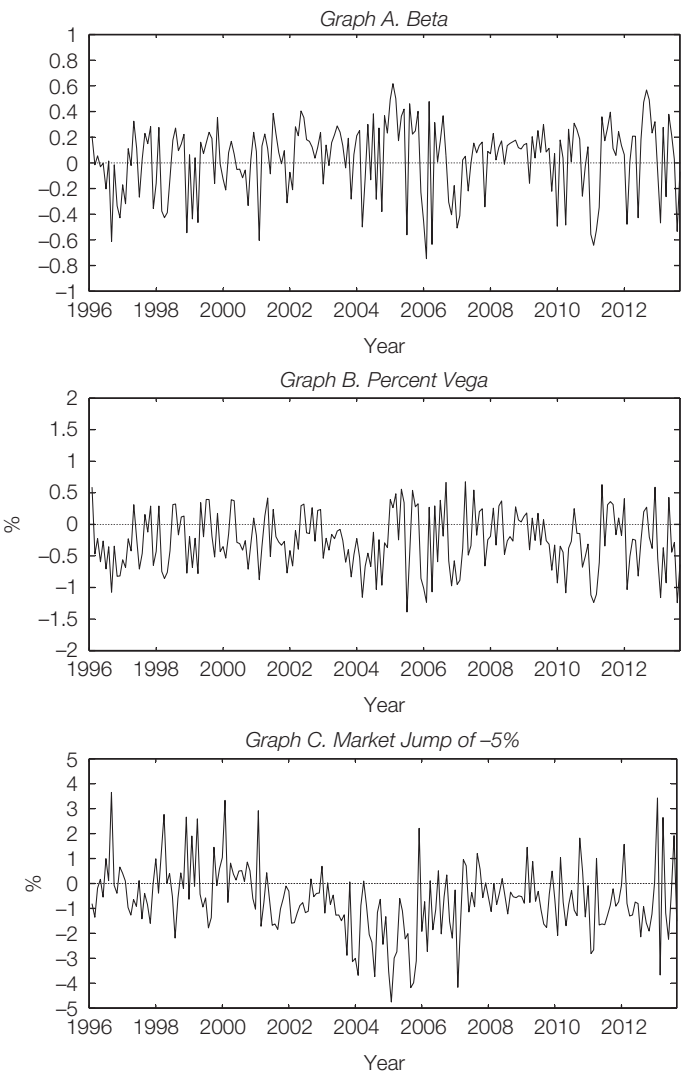

We use percent vega to proxy for the volatility exposure. Percent vega is the percentage change in the portfolio due to a 1-percentage-point change in volatility. This is generally low, varying between $-1.4 \%$ and $0.7 \%$. The mean percent vega is $-0.3 \%$ and significantly different from 0 using a Newey-West (1987) $t$-statistic. Therefore, if volatility increases by $1 \%$, the portfolio returns decrease by $0.3 \%$ on average. The magnitude of the exposure is low (and the sign changes often) so that the OOPS returns cannot be explained by the volatility risk premium only. Market jump of $-5 \%$ is the OOPS return from a sudden drop of $5 \%$ in the stock market. Jump risk at time $t$ for each option in the portfolio is computed as $O_{t}^{\mathrm{BS}}(S, \sigma)-O_{t}^{\mathrm{BS}}(0.95 S, \sigma)$ where $O_{t}^{\mathrm{BS}}$ is the Black-Scholes (1973) option value for each option in the strategy. We aggregate these exposures in the portfolio and present the result in percent. Market jump of $-5 \%$ evolves between $-4.8 \%$ and $3.7 \%$, and the average time-series value is $-0.6 \%$. This exposure is on average negative; that is, the strategy loses when there are large market drops, but the OOPS always loses less than the 
market. Therefore, the magnitude of the exposure is low (and the sign changes often) so that OOPS returns cannot be explained by the jump risk only. ${ }^{25}$ Therefore, the high OOPS returns cannot be fully explained as compensation for jump risk. From these ex ante measures it is clear that, on average, the OOPS is not particularly exposed to the market, volatility, or jump risks. This agrees with the low realized volatility, positive skewness, and low kurtosis of the OOPS ex post distribution discussed in the previous section.

To clarify the risk exposures of the OOPS even further, we present payoff profiles (the return of the portfolio as a function of S\&P 500 returns) for the timeseries average portfolio and three dates that present different weight profiles: June 2002, Apr. 2005, and Mar. 2007. Figure 8 presents these four payoff functions in Graphs A-D. The OOPS profile in June 2002 is little exposed to market risk. In Apr. 2005, the OOPS is exposed to low volatility. In Mar. 2010, the OOPS is exposed to left-tail risk. These three cases show the diversity of profiles of OOPS. On average, the OOPS time-series average profile is somewhat exposed to right-tail risk. We also present in Graphs E-H payoff profiles for four traditional strategies for comparison: short OTM put option, short ATM straddle, short 0-beta straddle, and short crash-neutral straddle, all delevered (4.47\% weight) so that they can be easily compared to the OOPS. The contrast is stark, especially in terms of the volatility exposure.

Next, we study the ex post risk exposure of the OOPS. First, we define the variables. EXCESS_MARKET_RETURN is the difference between the market return and the risk-free rate. As a proxy for the market return, we use the S\&P 500 index monthly return, $r_{\text {S\&P500 }}$. We proxy jump risk by a variable JUMP, equal to the value of the S\&P 500 index return when the monthly return is below $-5 \%$, and 0 otherwise. ${ }^{26}$ We consider two volatility measures: realized volatility (RV) of the previous month using daily data, and the VIX level (VIX). We also construct a proxy for the volatility risk premium, VRP, which is the spread between implied and realized volatilities (e.g., Adrian and Shin (2010), Saretto and Goyal (2009), among others). We use GAMMA, the second derivative of the option price with respect to the underlying stock. It proxies for nonlinear changes in the stock price. We use the slope of the implied volatility term structure, IV_TERM, defined as the 2-month ATM put implied volatility less the 1-month ATM put implied volatility. We also use the implied volatility moneyness slope, IV_MONEYNESS, defined as the 1-month OTM put implied volatility less 1-month ATM put implied volatility. All of these variables are customary in the equities and options literature. ${ }^{27}$

\footnotetext{
${ }^{25}$ We also address more extreme scenarios of market jump. A negative market jump of 2 (3) standard deviations, a drop of $8 \%(12 \%)$, results in an average time series of $-2.6 \%(-6.2 \%)$. A positive market jump of two (three) standard deviations, that is, an increase of $8 \%(12 \%)$, results in a average time series of $-3.9 \%(-5.9 \%)$. All these are relatively small. We also compute a combination of a large increase in volatility (50\% more) and a large drop in the market (a drop of 5\%). The average impact on the portfolio is of $-2.1 \%$, which is relatively small.

${ }^{26} \mathrm{We}$ also address more extreme scenarios. We run the same regressions with a market drop of 2 and 3 standard deviations. We do the same for a sudden increase of the same magnitude. The conclusions remain unchanged.

${ }^{27} \mathrm{We}$ also tried different explanatory variables and models. For example, there is insignificant exposure to the Carhart (1997) factors (http://mba.tuck.dartmouth.edu/pages/faculty/ken.french/), Fung-Hsieh (1997) hedge fund factors (http://faculty.fuqua.duke.edu/ dah7/HFData.htm), liquidity
} 
FIGURE 8

\section{Payoff Profile}

Figure 8 presents the effect of a percentage change in the stock market on several strategies. Graphs A-D are the timeseries average and three specific dates for the optimal option portfolio strategies (OOPS) allocation, and Graphs E-H represent traditional short strategies used in the literature related to market, volatility, and jump risk. OTM stands for out of the money, and ATM stands for at the money. The period is Jan. 1996 to Aug. 2013.
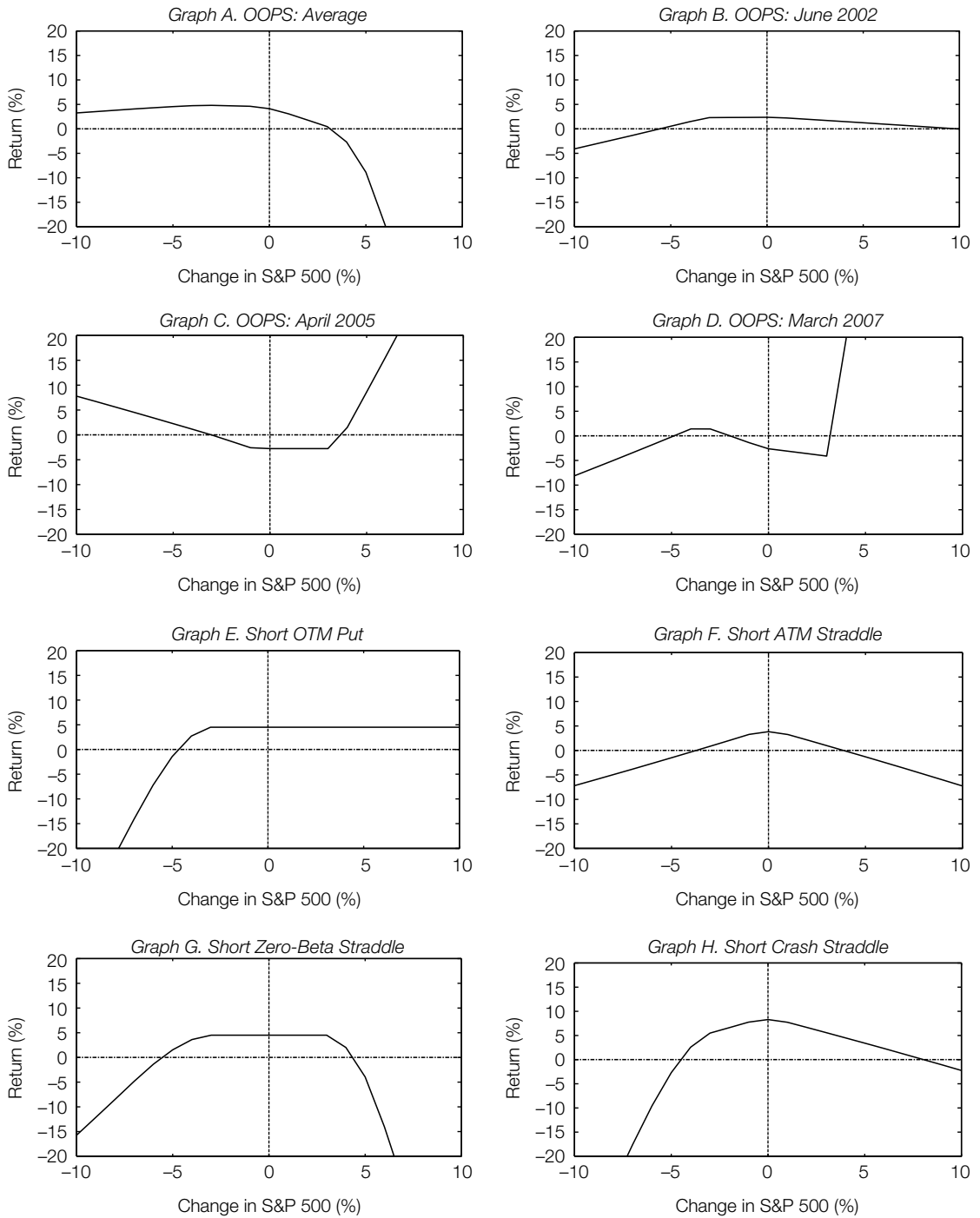

We run explanatory regressions of out-of-sample OOPS excess returns, $r_{t}-r f_{t}$, on contemporary risk variables, $X_{t}$ :

$$
r_{t}-r f_{t}=\alpha+\beta X_{t}+\epsilon_{t} .
$$

measures such as relative bid-ask spread or open interest, and the VOL and JUMP factors of Cremers, Halling, and Weinbaum (2015). 
We run simple linear regressions on traditional risk factors. The factors considered are excess market return, jump risk, and changes in the following variables: realized volatility, VIX, implied volatility term structure, and implied volatility moneyness slope. Table 7 reports the results. The market coefficient is positive and significant at the 5\% level. Therefore, the OOPS returns are positively related to market returns. The OOPS expected returns are negatively related to contemporaneous jump and changes in realized volatility. All of these estimates agree with previous ex ante risk measure findings. Notice that the magnitude of the coefficients on these variables are all low. This shows the low economic risk implied by exposure to market, volatility, or jump risks. Moreover, $R^{2}$ s are very low; that is, these variables are able to explain only a maximum of $4.99 \%$ of the variation in OOPS out-of-sample returns.

TABLE 7

Explanatory Regressions for OOPS Returns

Table 7 presents estimated coefficients ( $p$-values in square brackets) and the adjusted $R^{2}$ for explanatory regressions in which the dependent variable is the out-of-sample optimal option portfolio strategies (OOPS) excess returns, and the independent variable is the variable stated in the left column and defined in Section III. ** and *** indicate significance at the $5 \%$ and $1 \%$ levels, respectively. The period is Jan. 1996 to Aug. 2013, corresponding to 212 monthly observations.

OOPS Excess Returns

\begin{tabular}{|c|c|c|c|c|c|c|}
\hline Variable & 1 & 2 & 3 & 4 & 5 & 6 \\
\hline$r_{S \& P 500}-r_{f}$ & $\begin{array}{c}0.14^{\star \star} \\
{[0.04]}\end{array}$ & & & & & \\
\hline JUMP & & $\begin{array}{c}0.34^{\star \star \star \star} \\
{[0.00]}\end{array}$ & & & & \\
\hline$\Delta \mathrm{RV}$ & & & $\begin{array}{c}-0.07 \\
{[0.67]}\end{array}$ & & & \\
\hline$\Delta V I X$ & & & & $\begin{array}{c}-0.14 \\
{[0.51]}\end{array}$ & & \\
\hline$\triangle I V_{-}$TERM & & & & & $\begin{array}{c}-0.14 \\
{[0.49]}\end{array}$ & \\
\hline$\triangle I V \_M O N E Y N E S S$ & & & & & & $\begin{array}{c}-0.06 \\
{[0.87]}\end{array}$ \\
\hline $\bar{R}^{2}(\%)$ & 1.46 & 4.99 & -0.39 & -0.27 & -0.24 & -0.47 \\
\hline
\end{tabular}

Next, we study predictive regressions. We regress out-of-sample OOPS excess returns, $r_{t}-r f_{t}$, on a lagged variable $Z_{t-1}$, using the following regression:

$$
r_{t}-r f_{t}=\alpha+\beta Z_{t-1}+\epsilon_{t}
$$

These regressions study the conditional expected return of the strategy. We therefore use variables that proxy for conditional risk premia. The values at the beginning of the month for the following variables are used: realized volatility, VIX, variance risk premia, jump risk, gamma, implied volatility term, and implied volatility moneyness slope. Table 8 shows the results of these regressions. No variable is significant at the 5\% significance level. Moreover, these variables present a maximum $R^{2}$ of $0.41 \%$.

We conclude that there is no variable able to meaningfully explain the variation in expected or unexpected OOPS returns. Both the results using ex ante risk measures and payoff profiles and those using the ex post regressions are strong 
TABLE 8

Predictive Regressions for OOPS Returns

Table 8 presents estimated coefficients ( $p$-values in square brackets) and the adjusted $R^{2}$ for predictive regressions in which the dependent variable is the out-of-sample optimal option portfolio strategies (OOPS) excess returns and the independent variable is the variable stated in the left column and defined in Section III. The period is Jan. 1996 to Aug. 2013, corresponding to 212 monthly observations.

\begin{tabular}{|c|c|c|c|c|c|c|c|}
\hline \multirow[b]{2}{*}{ Variable } & \multicolumn{7}{|c|}{ OOPS Excess Returns } \\
\hline & 1 & 2 & 3 & 4 & 5 & 6 & 7 \\
\hline RV & $\begin{array}{c}0.07 \\
{[0.60]}\end{array}$ & & & & & & \\
\hline VIX & & $\begin{array}{c}0.17 \\
{[0.22]}\end{array}$ & & & & & \\
\hline VRP & & & $\begin{array}{c}0.32 \\
{[0.22]}\end{array}$ & & & & \\
\hline JUMP & & & & $\begin{array}{c}-0.03 \\
{[0.78]}\end{array}$ & & & \\
\hline GAMMA & & & & & $\begin{array}{c}-0.13 \\
{[0.17]}\end{array}$ & & \\
\hline IV_TERM & & & & & & $\begin{array}{c}-0.08 \\
{[0.73]}\end{array}$ & \\
\hline IV_MONEYNESS & & & & & & & $\begin{array}{c}-0.07 \\
{[0.85]}\end{array}$ \\
\hline $\bar{R}^{2}(\%)$ & -0.35 & 0.24 & 0.23 & -0.44 & 0.41 & -0.42 & -0.46 \\
\hline
\end{tabular}

evidence that OOPS returns are mostly based on exploiting the mispricing between options, rather than loading on priced risk factors. ${ }^{28}$

\section{Significance}

Broadie et al. (2009) question the significance of the abnormal returns of simple short option strategies. They show that empirically observed option returns are not inconsistent with what would have been obtained in a Black-Scholes (1973) world with no mispricing and no risk premia for volatility or crashes. We conduct a simulation study similar to theirs of a Black-Scholes economy under the objective measure. The calibration fits the historic behavior of the S\&P 500 index returns in our sample between 1950 and 2013. The historic average annualized index return is $7.17 \%$, the annualized volatility is $14.58 \%$, and the annualized risk-free rate is $1.74 \%$. This translates to a historic risk premium of $5.43 \%$ and a Sharpe ratio of 0.37 for the stock market, in line with the estimates in Broadie et al. In this economy there are no transaction costs. We simulate 1,000 paths of 756 months each (the sample length of our data) of the index level.

For each simulated path, we use the first 551 observations as the basis for the simulations used in the OOPS algorithm. These observations corresponds to the initial period between 1950 and 1995 in our sample. For each of the last 212 months, we price options with the moneyness as used in our empirical study using the Black-Scholes (1973) formula. Note that, by assumption, in this economy there is no mispricing or risk premia for crash and volatility risk factors. Then, we run the OOPS algorithm on these artificial samples. In the end, we compute the same time-series performance metrics as before, including the certainty equivalent and Sharpe ratio of the OOPS. In Figure 9, we plot the histograms of the difference between simulated OOPS and stock market Sharpe ratios (Graph A) and certainty equivalents (Graph B), as well as our point estimates reported in

\footnotetext{
${ }^{28}$ We study only linear risk factors. We scatter plot the OOPS returns against each risk factor to assess nonlinear dependencies. No pattern is recognized.
} 
FIGURE 9 Sampling Distribution of OOPS Sharpe Ratio and Certainty Equivalent
under a Black-Scholes Economy

Figure 9 presents histograms of the difference between the simulated optimal option portfolio strategies (OOPS) and simulated stock market Sharpe ratios (SR) (Graph A) and the difference of the simulated OOPS and simulated stock market certainty equivalents (CEs) (Graph B) under a Black-Scholes (1973) economy. The experiment uses 1,000 trajectories. The solid vertical line is the observed value from the data.
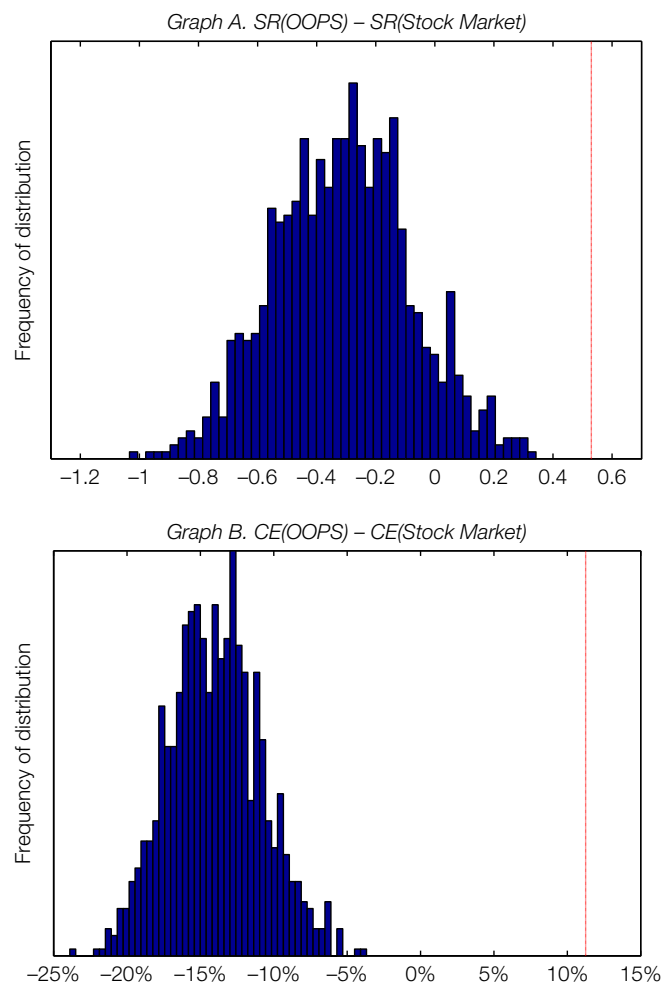

Table 4, which are represented by a dashed vertical line. The OOPS annualized Sharpe ratio and certainty equivalent are in the extreme right tail of the simulated distribution, showing clearly the significance of our estimates.

\section{Conclusion}

We offer a new method for portfolio optimization using options. This method takes into account the complex distribution of option returns and investor preferences for higher order moments. The method is straightforward to implement and requires virtually no computing resources. Our approach does not rely on a long time series of option returns but instead requires only currently observed prices. The approach takes into account the substantial transaction costs in this market in a simple and convenient manner.

We apply the method out of sample from 1996 to 2013 with impressive results. We obtain a high certainty equivalent and a large Sharpe ratio. We show that these results are driven mostly by exploiting option mispricings, coupled with a small exposure to market and volatility risk premia but not to crash risk. 


\section{Appendix. Example Implementation of the Method}

In this Appendix, we provide a small example of the method explained in Section II.A. In this small example, we assume two periods, $t=1,2$. At time 1 , we run the optimization problem and obtain the weights of each security. At time 2, we perform our out-of-sample exercise. We set the stock prices for this exercise as $S_{1}=1$ for period 1 and $S_{2}=0.98$ for period 2 , known only at period 2 . We also set the risk-free interest rate equal to $1 \%\left(r_{f}=0.01\right)$ for both periods. We use four options over the same underlying with the same maturity. The only difference between options is moneyness and the choice between call and put options. Hence, we define the two call options (at the money (ATM), $c_{1}$, and out of the money (OTM), $c_{2}$ ) and two put options (ATM, $p_{1}$, and OTM, $p_{2}$ ) with strike prices given by $K_{1, c_{1}}=K_{1, p_{1}}=1, K_{1, c_{2}}=1.05$, and $K_{1, p_{2}}=0.95$. The current option prices are $C_{1, c_{1}}=0.04, C_{1, c_{2}}=0.0008, P_{1, p_{1}}=0.07$, and $P_{1, p_{2}}=0.02$. We assume a power utility function with $\gamma=10$. In this example, we run our method for four simulations and we assume no transaction costs. Table A1 presents the results for each step of the method explained in Section II.A. In step 1, we assume the four simulated returns of 5\%, 1\%, $-4 \%$, and $-10 \%$. Then, in step 2, we compute the next-period underlying asset value. Using these four values, in step 3 we compute the simulated option payoffs at maturity and the corresponding returns for each option. In step 4, we compute the simulated portfolio returns. Based on these simulated portfolio returns, in step 5 we maximize the expected utility function and get the weights for each of the four options. In step 6, we determine the out-of-sample portfolio return. The resulting portfolio return for this hypothetical example is $3.60 \%$.

TABLE A1

\section{Example of the Method}

Table A1 shows an example of the method explained in Section II.A for a 2-period model with 4 simulations and assuming no transaction costs.

1. Simulate the underlying asset log-return

$r_{2}^{1}=0.0500 \quad r_{2}^{2}=0.0100$

2. Find the next-period underlying asset value

$S_{2 \mid 1}^{1}=1.0513 \quad S_{2 \mid 1}^{2}=1.0101$

3.a. Determine simulated option payoffs at maturity ...

$C_{2 \mid 1, C_{1}}^{1}=0.0513$

$C_{2 \mid 1, c_{2}}^{1}=0.0013$

$P_{2 \mid 1, p_{1}}^{1}=0.0000$

$P_{2 \mid 1, p_{2}}^{1}=0.0000$

$C_{2 \mid 1, c_{1}}^{2}=0.0101$

$C_{2 \mid 1, c_{2}}^{2}=0.0000$

$P_{2 \mid 1, p_{1}}^{2}=0.0000$

$P_{2 \mid 1, p_{2}}^{2 \mid 1, p_{1}}=0.0000$

$r_{2}^{3}=-0.0400$

$S_{2 \mid 1}^{3}=0.9608$

$C_{21, C_{1}}^{3}=0.0000$

$C_{21, c_{2}}^{3}=0.0000$

$P_{2 \mid 1, p_{1}}^{3}=0.0392$

$P_{2 \mid 1, p_{2}}^{3}=0.0000$

3.b. ... and corresponding returns for each option

$r_{2 \mid 1, c_{1}}^{1}=0.2818$

$r_{2 \mid 1, c_{2}}^{1}=0.5889$

$r_{2 \mid 1, p_{1}}^{1}=-1.0000$

$r_{2 \mid 1, p_{2}}^{1}=-1.0000$

$$
\begin{aligned}
& r_{2 \mid 1, c_{1}}^{2}=-0.7487 \\
& r_{2 \mid 1, c_{2}}^{2}=-1.0000 \\
& r_{2 \mid 1, p_{1}}^{2}=-1.0000 \\
& r_{2 \mid 1, p_{2}}^{2}=-1.0000
\end{aligned}
$$

4. Construct the simulated portfolio return

$r p_{2 \mid 1}^{1}=0.01$

$+\omega_{1, c_{1}} \times(0.2718)$

$+\omega_{1, c_{2}} \times(0.5789)$

$+\omega_{1, p_{1}} \times(-1.0100)$

$+\omega_{1, p_{2}} \times(-1.0100)$

$$
\begin{aligned}
& r p_{2 \mid 1}^{2}=0.01 \\
& \quad+\omega_{1, c_{1}} \times(-0.7587) \\
& \quad+\omega_{1, c_{2}} \times(-1.0100) \\
& \quad+\omega_{1, p_{1}} \times(-1.0100) \\
& \quad+\omega_{1, p_{2}} \times(-1.0100)
\end{aligned}
$$

$$
\begin{aligned}
& r_{211, c_{1}}^{3}=-1.0000 \\
& r_{2 \mid 1, c_{2}}^{3}=-1.0000 \\
& r_{211, p_{1}}^{3}=-0.4398 \\
& r_{2 \mid 1, p_{2}}^{3}=-1.0000
\end{aligned}
$$$$
r p_{2 \mid 1}^{3}=0.01
$$

$+\omega_{1, c_{1}} \times(-1.0100)$

$+\omega_{1, c_{2}} \times(-1.0100)$

$+\omega_{1, p_{1}} \times(-0.4498)$

$+\omega_{1, p_{2}} \times(-1.0100)$

$$
\begin{aligned}
& r_{2}^{4}=-0.1000 \\
& S_{2 \mid 1}^{4}=0.9048
\end{aligned}
$$

$C_{2 \mid 1, c_{1}}^{4}=0.0000$

$C_{2 \mid 1, c_{2}}^{4}=0.0000$

$P_{2 \mid 1, p_{1}}^{4}=0.0952$
$P_{2 \mid 1, p_{2}}^{4}=0.0452$

$r_{2 \mid 1, c_{1}}^{4}=-1.0000$

$r_{2 \mid 1, c_{2}}^{4}=-1.0000$

$r_{2 \mid 1, p_{1}}^{4}=0.3595$

$r_{2 \mid 1, p_{2}}^{4}=1.2581$

$$
\begin{aligned}
& r p_{2 \mid 1}^{4}=0.01 \\
& \quad+\omega_{1, c_{1}} \times(-1.0100) \\
& \quad+\omega_{1, c_{2}} \times(-1.0100) \\
& \quad+\omega_{1, p_{1}} \times(0.3495) \\
& \quad+\omega_{1, p_{2}} \times(1.2481)
\end{aligned}
$$

5. Choose weights by maximizing expected utility over simulated returns $\frac{1}{4} \sum_{n=1}^{4} \frac{\left(1+r p_{21}^{n}\right)^{-9}}{-9}$

$$
\omega_{1, c_{1}}=-0.10, \omega_{1, c_{2}}=0.07, \omega_{1, p_{1}}=-0.05, \omega_{1, p_{2}}=0.04 \text { and } E(U)=-0.0804
$$

6.a. Determine option actual payoffs ..

6.b. ... and returns for each option

$$
\begin{aligned}
& C_{2, c_{1}}=0.0000 C_{2, c_{2}}=0.0000 \\
& P_{2, p_{1}}=0.0200 P_{2, p_{2}}=0.0000
\end{aligned}
$$$$
r_{2, c_{1}}=-1.0000 r_{2, c_{2}}=-1.0000
$$$$
r_{2, p_{1}}=-0.7143 r_{2, p_{2}}=-1.0000
$$ 


\section{References}

Adrian, T., and H. S. Shin. "Liquidity and Leverage.” Journal of Financial Intermediation, 19 (2010), $418-437$.

Almazan, A.; K. Brown; M. Carlson; and D. Chapman. "Why Constrain Your Mutual Fund Manager?" Journal of Financial Economics, 73 (2004), 289-322.

Andersen, T. G.; L. Benzoni; and J. Lund. "An Empirical Investigation of Continuous Time Equity Return Models.” Journal of Finance, 57 (2002), 1239-1284.

Aragon, G. O., and J. S. Martin. "A Unique View of Hedge Fund Derivatives Usage: Safeguard or Speculation?” Journal of Financial Economics, 105 (2012), 436-456.

Baesel, J.; G. Shows; and E. Thorp. "The Cost of Liquidity Services in Listed Options." Journal of Finance, 38 (1983), 989-995.

Bakshi, G.; C. Cao; and Z. Chen. "Empirical Performance of Alternative Option Pricing Models." Journal of Finance, 52 (1997), 2003-2049.

Barone-Adesi, G.; R. F. Engle; and L. Mancini. "A GARCH Option Pricing Model with Filtered Historical Simulation.” Review of Financial Studies, 21 (2008), 1223-1258.

Barone-Adesi, G.; K. Giannopolos; and L. Vosper. "VaR without Correlations for Non-Linear Portfolios." Journal of Futures Markets, 19 (1999), 583-602.

Bates, D. "Jump and Stochastic Volatility: Exchange Rate Processes Implicit in Deutsche Mark Options." Review of Financial Studies, 9 (1996), 69-107.

Bernardo, A. E., and O. Ledoit. "Gain, Loss, and Asset Pricing." Journal of Political Economy, 108 (2000), 144-172.

Black, F., and M. Scholes. "The Pricing of Options and Corporate Liabilities." Journal of Political Economy, 81 (1973), 637-659.

Bliss, R. R., and N. Panigirtzoglou. "Option-Implied Risk Aversion Estimates.” Journal of Finance, 59 (2004), 407-446.

Bondarenko, O. "Why Are Puts So Expensive?" Working Paper, University of Illinois at Chicago (2003).

Brandt, M. W. "Estimating Portfolio and Consumption Choice: A Conditional Euler Approach." Journal of Finance, 54 (1999), 1609-1645.

Brandt, M. W.; P. Santa-Clara; and R. Valkanov. "Parametric Portfolio Policies: Exploiting Characteristics in the Cross Section of Equity Returns." Review of Financial Studies, 22 (2009), 3411-3447.

Broadie, M.; M. Chernov; and M. Johannes. "Model Specification and Risk Premia: Evidence from Futures Options.” Journal of Finance, 62 (2007), 1453-1490.

Broadie, M.; M. Chernov; and M. Johannes. "Understanding Index Option Returns." Review of Financial Studies, 22 (2009), 4493-4529.

Buraschi, A., and J. Jackwerth. "The Price of a Smile: Hedging and Spanning in Option Markets." Review of Financial Studies, 14 (2001), 495-527.

Carhart, M. M. "On Persistence in Mutual Fund Performance.” Journal of Finance, 52 (1997), 57-82.

Chen, Y. "Derivatives Use and Risk Taking: Evidence from the Hedge Fund Industry." Journal of Financial and Quantitative Analysis, 46 (2011), 1073-1106.

Chernov, M., and E. Ghysels. "A Study Towards a Unified Approach to the Joint Estimation of Objective and Risk Neutral Measures for the Purpose of Options Valuation." Journal of Financial Economics, 56 (2000), 407-458.

Christoffersen, P.; K. Jacobs; and S. L. Heston. "Capturing Option Anomalies with a Variance Dependent Pricing Kernel.” Review of Financial Studies, 26 (2013), 1963-2006.

Constantinides, G. M.; J. C. Jackwerth; and A. Z. Savov. "The Puzzle of Index Option Returns." Review of Asset Pricing Studies, 3 (2013), 1-29.

Coval, J. D., and T. Shumway. "Expected Option Returns.” Journal of Finance, 56 (2001), 983-1009.

Cremers, M.; M. Halling; and D. Weinbaum. "Aggregate Jump and Volatility Risk in the Cross-Section of Stock Returns.” Journal of Finance, 70 (2015), 577-614.

Deli, D. N., and R. Varma. "Contracting in the Investment Management Industry: Evidence from Mutual Funds." Journal of Financial Economics, 63 (2002), 79-98.

DeMiguel, V.; L. Garlappi; and R. Uppal. "Optimal versus Naive Diversification: How Inefficient Is the 1/N Portfolio Strategy?” Review of Financial Studies, 22 (2009), 1915-1953.

Dennis, P., and S. Mayhew. "Microstructural Biases in Empirical Tests of Option Pricing Models." Review of Derivatives Research, 12 (2009), 169-191.

Diebold, F. X.; T. Schuermann; and J. D. Stroughair. "Pitfalls and Opportunities in the Use of Extreme Value Theory in Risk Management." In Decision Technologies for Computational Finance, A.-P. N. Refenes, A. N. Burgess, and J. D. Moody, eds. Amsterdam: Kluwer Academic (1998), 3-12.

Driessen, J., and P. Maenhout. "An Empirical Portfolio Perspective on Option Pricing Anomalies." Review of Finance, 11 (2007), 561-603. 
Driessen, J., and P. Maenhout. "The World Price of Jump and Volatility Risk." Journal of Banking \& Finance, 37 (2013), 518-536.

Duffie, D.; J. Pan; and K. Singleton. "Transform Analysis and Asset Pricing for Affine JumpDiffusions." Econometrica, 68 (2000), 1343-1376.

Efron, B., and R. J. Tibshirani. An Introduction to the Bootstrap. New York: Chapman \& Hall (1993).

Eraker, B. "Do Stock Prices and Volatility Jump? Reconciling Evidence from Spot and Option Prices." Journal of Finance, 59 (2004), 1367-1403.

Eraker, B. "The Performance of Model Based Option Trading Strategies." Review of Derivatives Research, 16 (2013), 1-23.

Fung, W., and D. A. Hsieh. "Empirical Characteristics of Dynamic Trading Strategies: The Case of Hedge Funds." Review of Financial Studies, 10 (1997), 275-302.

Hull, J., and A. White. "Incorporating Volatility Updating into the Historical Simulation Method for Value-at-Risk." Journal of Risk, 1 (1998), 5-19.

Ingersoll, J.; M. Spiegel; W. Goetzmann; and I. Welch. "Portfolio Performance Manipulation and Manipulation-Proof Performance Measures.” Review of Financial Studies, 20 (2007), 1503-1546.

Jackwerth, J. "Recovering Risk Aversion from Option Prices and Realized Returns." Review of Financial Studies, 13 (2000), 433-451.

Jones, C. "A Nonlinear Factor Analysis of S\&P 500 Index Option Returns." Journal of Finance, 61 (2006), 2325-2363.

Koski, J. L., and J. Pontiff. "How Are Derivatives Used? Evidence from the Mutual Fund Industry." Journal of Finance, 54 (1999), 791-816.

Liu, J., and J. Pan. "Dynamic Derivative Strategies.” Journal of Financial Economics, 69 (2003), $401-430$.

Ljung, G. M., and G. E. P. Box. "On a Measure of a Lack of Fit in Time Series Models.” Biometrika, 65 (1978), 297-303.

Malamud, S. "Portfolio Selection with Options and Transaction Costs." Swiss Finance Institute Research Paper No. 14-08 (2014).

Michaud, R. O., and R. Michaud. "Estimation Error and Portfolio Optimization: A Resampling Solution." Journal of Investment Management, 6 (2008), 8-28.

Newey, W. K., and K. D. West. "A Simple, Positive Semi-Definite, Heteroskedasticity and Autocorrelation Consistent Covariance Matrix.” Econometrica, 55 (1987), 703-708.

Pan, J. "The Jump-Risk Premia Implicit in Options: Evidence from an Integrated Time-Series Study." Journal of Financial Economics, 63 (2002), 3-50.

Phillips, S., and C. Smith. "Trading Costs for Listed Options: The Implications for Market Efficiency." Journal of Financial Economics, 8 (1980), 179-201.

Plyakha, Y., and G. Vilkov. "Portfolio Policies with Stock Options." SSRN Working Paper (2008).

Ross, S. "Options and Efficiency." Quarterly Journal of Economics, 90 (1976), 75-89.

Saretto, A., and A. Goyal. "Cross-Section of Option Returns and Volatility." Journal of Financial Economics, 94 (2009), 310-326.

Saretto, A., and P. Santa-Clara. "Option Strategies: Good Deals and Margin Calls.” Journal of Financial Markets, 12 (2009), 391-417.

Tan, S. "The Role of Options in Long Horizon Portfolio Choice.” Journal of Derivatives, 20 (2013), $60-77$.

Todorov, V. "Variance Risk Premium Dynamics: The Role of Jumps.” Review of Financial Studies, 23 (2010), 345-383.

Vanden, J. "Options Trading and the CAPM.” Review of Financial Studies, 17 (2004), 207-238. 